\title{
Joint Culpability: The Effects of Medical Marijuana Laws on Crime
}

\author{
Yu-Wei Luke Chu \\ luke.chu@vuw.ac.nz \\ School of Economics and Finance \\ Victoria University of Wellington \\ Wilbur Townsend \\ wilb@stanford.edu \\ Stanford Institute for Economic Policy Research \\ Stanford University
}

Most U.S. states have passed medical marijuana laws. In this paper, we study the effects of these laws on violent and property crime. We first estimate fixed effects models that control for flexible city-specific time trends. To supplement this regression analysis, we use the synthetic control method which can relax the parallel trend assumption and better account for heterogeneous policy effects. Both the regression analysis and the synthetic control method suggest no causal effects of medical marijuana laws on violent or property crimes at the national level. We also find no strong effects within individual states, except for in California where the medical marijuana law reduced both violent and property crime by $20 \%$. 
"A young boy who had become addicted to smoking marihuana cigarettes ... seized an ax and killed his father, mother, two brothers, and a sister.” Harry J. Anslinger, Commissioner of Narcotics, Additional Statement for the Marihuana Tax Act of 1937.

\section{Introduction}

There is a strong correlation between marijuana use and criminal activity (Bennett, Holloway, and Farrington 2008), and marijuana is the drug most commonly detected among arrestees. ${ }^{1}$ This association is one reason that the U.S. Federal Government continues to classify marijuana as a Schedule I drug (Drug Enforcement Administration 2011). However, the causal evidence on the effects of marijuana use on crime is limited and inconclusive (Adda, McConnell, and Rasul 2014; Braakmann and Jones 2014; Fergusson and Horwood 1997; Green et al. 2010; Markowitz 2005; Norström and Rossow 2014; Pacula and Kilmer 2003).

Since 1996, most U.S. states and the District of Columbia have legalized medical marijuana. A medical marijuana law protects patients whose marijuana use has been recommended by a doctor from being convicted of marijuana possession. Several recent studies have shown that medical marijuana laws cause a 10-20\% increase in marijuana use, concentrated among heavy users and older adults (Chu 2014, 2015; Hasin et al. 2017; Martins et al. 2016; Wen, Hockenberry, and Cummings 2015). Somewhat surprisingly, there is little evidence that medical marijuana laws have increased marijuana use among adolescents. (For a review of the literature, see Sarvet et al. (2018).) A growing literature evaluating whether medical marijuana laws affect health and social outcomes has found that medical marijuana laws reduce drunk driving, heroin usage, opioid addiction, obesity, suicide, and time spent on study (Anderson, Hansen, and Rees 2013; Anderson, Rees, and Sabia 2014; Chu 2015; Chu and Gershenson 2016; Powell, Pacula, and Jacobs 2015; Sabia, Swigert, and Young 2017).

There are several channels through which medical marijuana laws could affect crime. The increase in marijuana use could decrease crime rates because marijuana use directly reduces aggression and violence (Miczek et al. 1994). However, the long-run neuropsychological effects of marijuana could harm the brain, causing violent behaviors (Boles and Miotto 2003; Hoaken and Stewart 2003; Macleod et al. 2004;

\footnotetext{
${ }^{1}$ For example, the annual report of the Arrestee Drug Abuse Monitoring Program II shows that 30-60\% of adult male arrestees tested positive for marijuana use in 2013 (Office of National Drug Control Policy 2014).
} 
Meier et al. 2012; Moore and Stuart 2005; Ostrowsky 2011; Volkow et al. 2014). MRI images show brain abnormities even among casual and abstinent users (Bolla et al. 2005; Gilman et al. 2014; Raver, Haughwout, and Keller 2013). Medical marijuana laws sometimes permit marijuana dispensaries. These dispensaries may shrink the marijuana black market and its associated violence. Dispensaries may also deter crime as they are required to deal in cash and thus invest heavily in security (Chang and Jacobson 2011; Kepple and Freisthler 2012). Finally, medical marijuana laws could reallocate police resources towards deterring crime instead of enforcing drug laws (Adda, McConnell, and Rasul 2014).

The studies estimating the effects of medical marijuana laws on crime have found mixed results (Alford 2014; Gavrilova, Kamada, and Zoutman 2018; Huber, Newman, and LaFave 2016; Morris et al. 2014). For example, Huber, Newman, and LaFave (2016) find a 15-20\% decrease in both violent and property crimes, while Morris et al. (2014) report small and insignificant estimates. Gavrilova, Kamada, and Zoutman (2018) find a 12\% reduction in violent crimes in the three medical marijuana states bordering to Mexico and insignificant changes elsewhere.

Given the mixed results in the literature it is unclear whether medical marijuana laws affect crime rates. One limitation of the existing literature is that it relies on the state or county level crime data from the Uniform Crime Reports (UCR), which contain substantial measurement error. Because participation in the UCR program is generally voluntary, and many police agencies do not report every year, the composition of reporting agencies in each state or county is not constant over time. Another limitation is that some states exhibit strong distinctive trends in crime, suggesting that the parallel trend assumption required in difference-in-difference regression may be unjustified. A third limitation is that medical marijuana laws differ, and as such may have heterogeneous effects (Anderson and Rees 2014; Pacula, Boustead, and Hunt 2014; Pacula et al. 2015). One important implication of heterogeneous effects is that, as the existing studies often use state populations to weight their regressions, their results could be driven by a few large states (Solon, Haider, and Wooldridge 2015).

In this paper we estimate the causal effects of medical marijuana laws on violent and property crimes using the UCR offense data for the years 1988-2013. To minimize measurement error, we use agency-level data from cities of more than 50,000 city residents, with whom the FBI communicates regularly (Akiyama and Propheter 2005). We first apply a difference-in-difference research design implemented by a linear 
regression model which controls for city fixed effects and flexible city-specific time trends. We then use the synthetic control method which can nonparametrically control for pre-law differences in crime trends and thus can relax the parallel trend assumption (Abadie, Diamond, and Hainmueller 2010, 2011). The synthetic control method can also investigate treatment effect heterogeneity by estimating causal effects within individual cities or states. We apply the synthetic control method at the city level to be consistent with the regression analysis and to minimize measurement error. We obtain synthetic controls for each medical marijuana city and calculate difference-indifference estimates of medical marijuana laws' effect in each city. To obtain the aggregate effects, we first average city-level estimates to obtain the state-level estimated effects of each medical marijuana law then average state-level effects to the national level. Since we are mainly interested in the state or national average effects of medical marijuana laws, we implement a generalized placebo method proposed by Cavallo et al. (2013) to perform statistical inference on these average estimates.

Both the regression analysis and the synthetic control find no substantial changes - positive or negative - in either violent or property crime after the passage of medical marijuana laws. Most of the regression estimates are small and insignificant. The estimates are somewhat sensitive to model specifications of the city-specific time trends, suggesting that the parallel trend assumption presumed in the existing literature may be failing. The estimated effects also appear to be somewhat heterogeneous across states: the signs of the estimates change when California is excluded from the sample. The results from the synthetic control method are broadly consistent with the regression analysis but are more robust and precisely estimated. At the national level, both before and after the passage of medical marijuana laws, the violent and property crime rates in the medical marijuana states are nearly identical to those in their synthetic controls, suggesting medical marijuana laws had no effect. The difference-in-difference estimates derived from the synthetic control are very small and are statistically insignificant: they indicate only a 3.7\% decrease in violent crime and a $1.5 \%$ increase in property crimes.

We also use the synthetic control method to investigate the effects of medical marijuana laws on specific crimes: murder, rape, robbery, aggravated assault, burglary, larceny, and motor vehicle theft. Most of the estimates are close to zero except for the estimated effect on motor vehicle theft, which indicates an increase of $8.1 \%$. At the state level we find only modest heterogeneity in the estimated effects; in most medical 
marijuana states, violent and property crimes generally do not deviate from their synthetic controls. One distinctive exception is California in which both violent and property crimes decrease by around $20 \%$ after the enactment of a medical marijuana law. Overall, our findings suggest no strong causal relationship between medical marijuana laws and criminality.

This paper resolves the discrepancies in the existing literature and addresses an important policy issue - medical marijuana laws' effects on crime - using both a traditional regression analysis and a nonparametric method, the synthetic control. In evaluating these laws we also provide plausible evidence on the causal relationship between marijuana use and criminal activity. Perhaps because marijuana use among adolescents, the age group with a higher risk of committing crimes, remain unchanged (Sarvet et al. 2018), or because the marijuana black market generates little violence (Caulkins and Pacula 2006; Reuter 2009), we do not find that medical marijuana legalization affect crime. As the legalization of recreational marijuana becomes increasingly popular, the lack of a positive causal effect of marijuana use on crime may ease public concerns.

The paper proceeds as follows: Sections 2 and 3 describe the medical marijuana laws and the UCR data. Section 4 presents the results from the regression models, and Section 5 presents the results from the synthetic control method. Section 6 concludes.

\section{Medical Marijuana Laws}

As of 2016, 28 states and the District of Columbia have passed medical marijuana laws (ProCon.org 2017). ${ }^{2}$ States with effective medical marijuana laws and the years these laws became legally effective are listed in Table 1. A medical marijuana law allows doctors to recommend (not prescribe) marijuana to patients, and prevents patients who have received a recommendation from being convicted of marijuana possession. In states which have legalized medical marijuana, marijuana user groups advertise the contact details of "cannabis physicians." ${ }^{3}$ In most states, individuals need to register with the state medical marijuana program to become a legal patient and

\footnotetext{
${ }^{2}$ Smoking is not a method approved by the medical marijuana laws in Minnesota, New York, Ohio and Pennsylvania. In addition, there are 16 states with laws that specifically allow the use of cannabidiol, but these laws are not considered medical marijuana laws because they do not legalize use of the marijuana plant. For a list of these 16 states that allow the use of cannabidiol, see http://medicalmarijuana.procon.org/view.resource.php?resourceID=006473.

${ }^{3}$ See for example the directory operated by California NORML: http://www.canorml.org/prop/physlistinfo.html.
} 
obtain a medical marijuana card. ${ }^{4}$ The number of registered patients was relatively small before 2009 but has increased dramatically since. An estimate from ProCon.org (2016) suggests that there are about 1.2 million registered patients in 2016, roughly $0.8 \%$ of the population of medical marijuana states. While some laws stipulate an exhaustive list of uses for which medical marijuana can be recommended, others allow for "any... illness for which marijuana provides relief" (California Health \& Safety Code Ann. §11362.5). Those which do dictate the uses for which marijuana can be recommended tend to allow for pain alleviation (ProCon.org 2017), though they differ as to whether that pain must be from a diagnosable medical condition (Pacula, Boustead, and Hunt 2014).

Medical marijuana laws passed prior to the Obama administration generally do not authorize marijuana dispensaries, as marijuana remains a Schedule I drug under federal classification. Instead, these medical marijuana laws let patients grow marijuana on a not-for-profit basis. Marijuana dispensaries with grey legal status still exist, notably in California and Colorado. ${ }^{5}$ The existence of dispensaries largely depends on the attitudes of local government and law enforcement, which can be unstable. For example, Los Angeles closed more than 400 dispensaries in 2010 (Barco 2010). In 2007, New Mexico became the first state to pass a medical marijuana law with a provision to license production and distribution at the state level, but the first state-licensed marijuana provider in New Mexico was not approved until March 2009. In 2009, the Obama administration announced that the Federal Government would no longer arrest medical marijuana users and suppliers provided they complied with state laws (Mikos 2011). Dispensaries started to be regulated and protected by state laws, and the numbers of both dispensaries and registered patients have increased significantly.

\section{UCR data}

In this paper we use the Uniform Crime Reports (UCR), an administrative series produced by the FBI collating monthly police records from state and local police agencies. We use the UCR offense data from the Inter-university Consortium for

\footnotetext{
${ }^{4}$ California, Maine, and Washington had created registration programs but registration remains voluntary. Some states such as Colorado and Nevada allow patients who do not join the registry to argue an "affirmative defense of medical necessity."

${ }^{5}$ Dispensaries are considered to be legally protected in California and Colorado. Their laws recognize the existence of dispensaries even though they are silent as to their legality (Pacula, Boustead, and Hunt 2014).
} 
Political and Social Research. The offense data provide the number of criminal offenses reported to the police, excluding those the police agency deems unfounded. As California became the first U.S. state to pass a medical marijuana law in 1996, to establish pre-law crime trends we use data from 1988. The latest year for which the UCR data was available when we started this research project was 2013. Consequently, we use the UCR offense data for the years 1988-2013.

Since participation in the UCR program is generally voluntary, many agencies do not report every month or every year, and they may not report data in all categories. ${ }^{6}$ To minimize measurement error we use agency-level data and aggregate from monthly to yearly data. Agencies policing cities with more than 50,000 residents communicate with the FBI more regularly (Akiyama and Propheter 2005). Lynch and Jarvis (2008) indicate that most of these bigger cities were reporting to the FBI monthly. To avoid endogenous sample selection we use police agencies responsible for cities with at least 50,000 residents in any year of the sample period. ${ }^{7,} 8$ (We exclude 423 city-year observations that have less than 25,000 residents.) As the UCR data does not distinguish between true zeros and missing data, we make two assumptions. First, we assume zeros for total violent crime or total property crime in our sample represent missing data - a reasonable assumption for these relatively large cities. Second, we assume zeros in each crime category are true zeros when the total violent or property crime count is not zero. As nearly all of the zeros come from the most severe violent crime - murder - these zeros are unlikely to be missing data.

In the UCR offense data there are four categories of violent crimes - murder, forcible rape, robbery and aggravated assault - and four categories of property crimes - burglary, larceny theft, motor vehicle theft and arson. We exclude arson because the arson data is very incomplete. We sum over the other categories to obtain the total violent and property crime rates per 100,000 city residents which will be our main focus in the paper. We merge the offense data with police officer counts from the UCR Law Enforcement Officers Killed and Assaulted series. The final panel consists of 18,607

\footnotetext{
${ }^{6}$ The UCR offense data only indicates the month of the last report, but it does not necessarily mean that the agency reports every month prior to the last reported month. We exclude 321 observations for which the last reported month is not December.

${ }^{7}$ We focus on cities and exclude counties. Among agencies in metropolitan statistical areas with more than 50,000 residents about $70 \%$ of the population lives in cities.

${ }^{8}$ We also exclude one city in Alaska, Fairbank, which experienced a fast drop in population and a surge in crime. Fairbank has a population of only roughly 30,000 since 1990 and data quality is often a concern in small cities.
} 
city-year observations. There are 825 cities from 49 states and the District of Columbia, where 315 cities from 18 jurisdictions (17 states and the District of Columbia) experience a medical marijuana law. One medical marijuana state, Vermont, is not in the sample because no city from Vermont in the UCR has population greater than 50,000 . About $61 \%$ of the cities are observed in every year, and $88 \%$ of the cities are observed in at least 23 years. Summary statistics for violent and property crime rates per 100,000 city residents, as well as the summary statistics for each crime, are reported in Appendix Table A1.

\section{Regression Analysis}

\subsection{Model}

We first implement a difference-in-difference research design by estimating the following linear model using OLS:

$$
\log (\text { crime })_{i s t}=\beta \cdot M M L_{s t}+\gamma \cdot X_{i s t}+\theta_{i}+\delta_{t}+f_{i t}(t)+\varepsilon_{i s t}
$$

in which the dependent variable is the logarithm of the violent or property crime rate in city $i$, state $s$ and year t. $M M L_{s t}$ is a binary indicator equal to one if state $s$ had a medical marijuana law in effect in year $t$ and zero otherwise. $X_{\text {ist }}$ is a vector of timevarying city and state characteristics including log agency population, log agency police officer counts, log state unemployment rates, and dummy variables for marijuana decriminalization and marijuana legalization. ${ }^{9} \theta_{i}$ and $\delta_{t}$ are city and year fixed effects, $f_{i t}(t)$ is a city-specific time trend with a linear, quadratic or cubic functional form, and $\varepsilon_{i s t}$ is the idiosyncratic error term. The parameter of interest is $\beta$, the causal effect of state medical marijuana laws on log crime rates. Abadie et al. (2017) suggest that clustering should be treated as an issue of research design. As medical marijuana laws are determined at the state level, the estimated standard errors allow within-state clustering.

\subsection{Results}

Table 2 presents estimated effects of medical marijuana laws on total violent crime. In column (1), which displays results controlling for linear city-specific time

\footnotetext{
${ }^{9}$ States that decriminalize marijuana possession in our sample period are California (in 2011), Connecticut (in 2012), and Massachusetts (in 2009). States that legalize marijuana are Colorado and Washington (both in 2013). All policy indicators equal one in the first full year of a policy being effective and thereafter. (Since the medical marijuana laws in Massachusetts and Rhode Island became effective in January, the years of enactment were treated as the first full year.)
} 
trends, the estimate is very close to zero. In column (2), in which we control for quadratic trends, the estimate becomes statistically significant at the $5 \%$ level and indicates that medical marijuana laws cause a $4.7 \%$ decrease in violent crime rates. In column (3), in which we control for cubic trends, the point estimate changes little but its estimated standard error grows and as such it loses its significance.

The policy indicator $M M L_{\text {st }}$ varies at the state level while each observation is a city-year. As such, one concern is that the estimates in columns (1) - (3) could be driven by a few populous states with many cities. ${ }^{10}$ To illustrate this problem we report estimates in columns (4) - (6) in which the largest state, California, is omitted from the sample. Unlike the estimates in columns (1) - (3), the estimates in columns (4) - (6) are small and insignificant, suggesting no causal relationship between medical marijuana laws and violent crime. While the estimates in columns (4) - (6) are all close to zero, the remaining differences between them demonstrate their sensitivity to the functional form of the city-specific time trends, suggesting that the parallel trend assumption may not be justified. In columns (7) - (9) we aggregate the data to the state level and re-estimate the model to obtain an average estimated effect - that is, one in which each medical marijuana state receives equal weight regardless of its number of cities. These regressions are more consistent with the underlying research design because medical marijuana laws vary at the state level. Similar to columns (4) - (6), all of the estimates in columns (7) - (9) are statistically insignificant and are quite sensitive to time tend specifications. That the estimates in latter columns differ from those in columns (1) - (3) suggests that state-specific effects of medical marijuana laws on violent crime are somewhat heterogeneous. ${ }^{11}$ As most existing studies use populationweighted regressions or less aggregated data in which the number of observations is

\footnotetext{
${ }^{10}$ In a linear model in which the explanatory variables vary only at the group level, the ordinary least squares estimates are numerically identical to the weighted least squares estimates from a group-level regression using group averages in which the weights are the numbers of observations in each group. Therefore, the estimates in columns (1) - (3) could be viewed as weighted least square estimates disproportionately identified by states with more cities.

${ }^{11}$ The estimates from population-weighted city-level regressions are quantitatively similar to those from unweighted city-level regressions reported in Table 2 and 3, suggesting that there is little heterogeneity within a state (for these relatively large cities). The estimates from state-level regressions weighted by state population are close to those from city-level regressions (both weighted and unweighted) as they are disproportionately identified by states with large populations and thus more cities. These results are available upon request.
} 
larger in more populous states, as is the case in the regressions reported in columns (1) - (3), their negative effects may be driven by large states like California. ${ }^{12}$

Table 3 presents estimated effects on property crime. The city-level estimates including California (columns (1) - (3)) are negative but small and insignificant. However, the city-level estimates excluding California (columns (4) - (6)) are positive and statistically significant, suggesting a 3.8-6.2\% increase in property crime rates. The state-level estimates in columns (7) - (9) are also positive though they are not statistically significant. The difference in the estimated effects between the city-level regression and state-level regression again seems to be mainly due to the weighting of California. Unlike the estimates for violent crime, the estimates for property crime are less sensitive to the time trend specification.

We do not find evidence that medical marijuana laws consistently affect violent and property crimes. We use agency-level data from relatively large cities and thus our results should be less sensitive to measurement error than previous studies which use aggregate state or county level data. However, the results still appear to be somewhat sensitive to time trend specifications and to the implicit weight given to each medical marijuana state. The mixed findings in previous studies are likely due to heterogeneity in the medical marijuana laws' effects or to the failure of the parallel trend assumption. In the Appendix Tables A2 and A3, we replace the policy indicator $M M L_{s t}$ with a set of dummy variables that indicate each year before (Year -1 to Year -5) and after (Year 0 to Year 7+) the passage of medical marijuana laws to estimate dynamic effects of these laws on violent and property crimes. The estimates for pre-law dummies Year -1 to Year -5 are often large and statistically significant especially when California is included in the sample, suggesting that violent and property crimes in medical marijuana states and non-medical marijuana states exhibit distinct trends and thus the parallel trend assumption required by the difference-in-difference design may not be valid. In the next section, we apply the synthetic control method which can address these concerns.

\section{Synthetic Control Analysis}

\footnotetext{
${ }^{12}$ For example, Huber, Newman, and LaFave (2016) estimate state-level regression weighted by state population, and Gavrilova, Kamada, and Zoutman (2018) estimate county-level regressions weighted by county population. The estimate in Gavrilova, Kamada, and Zoutman (2018) decreases by 35\% when counties with more than 250,000 residents are excluded (in their online appendix, Table D6).
} 


\subsection{Methodology}

The synthetic control method compares a treated unit to its synthetic control: a weighted average of units from a potential control group (the "donor pool”) with weights chosen to minimize pre-treatment differences between the treated unit and the synthetic control (Abadie, Diamond, and Hainmueller 2010, 2011; Abadie and Gardeazabal 2003). The synthetic control provides the best available counterfactual to the treated unit because the synthetic control is constructed to match the treated unit as closely as possible. ${ }^{13}$ The synthetic control method can be viewed as a generalization of difference-in-difference research design: a fixed effects regression with a single treatment unit is equivalent to a synthetic control which places equal weight on all units from the control group. Unlike regression analysis that can only control for time trends using parametric functional forms, the synthetic control method can nonparametrically remove pre-existing trends. Moreover, as the synthetic control method constructs the optimal control for each treated unit, it can better estimate (potentially heterogeneous) state-specific treatment effects.

We use the synthetic control method to estimate the causal effects of medical marijuana laws on violent and property crimes. In addition to the dependent variable, $\log$ violent or property crime rates, we use log police officer counts and log city populations (for each pre-treatment year) to fit the synthetic control. Each treated unit is a city from a medical marijuana state and the donor pool consists of cities from states without an effective medical marijuana law in 2013. Units in the synthetic control's donor pool need to form a balanced panel without missing data. To retain a large, balanced donor pool we implement the synthetic control method using a 15-year interval - 7 years before and after (the first full year of) the implementation of a law. We require each treated city to have at least 5 years of non-missing pre-treatment data. 315 treated cities are retained. As the medical marijuana laws were passed in different years, treated cities’ donor pools differ.

\footnotetext{
${ }^{13}$ The identification assumption required by difference-in-difference estimation is that the changes in the treatment group and control group would be identical if not for the treatment. Strictly speaking, the similarity of pre-treatment outcome variable between the treatment and control groups is neither a sufficient nor a necessary condition for identification of the treatment effect using difference-indifference estimation. For sufficient conditions for the unbiasedness of synthetic control estimation see Abadie, Diamond, and Hainmueller (2010).
} 
The synthetic control method was designed to identify causal effects with a single treatment unit for which large-sample standard errors are not available. ${ }^{14}$ To conduct inference, Abadie, Diamond, and Hainmueller (2010) suggest a placebo method which compares the actual estimate to the empirical distribution of placebo estimates, with placebo estimates calculated by constructing synthetic controls for each unit in the donor pool. Intuitively, if many placebo estimates are greater than the actual estimate, the actual estimate is plausibly drawn from the same distribution as the placebo effects and the estimated effect is not due to the policy change. As medical marijuana laws are implemented at the state level we are interested in national or statelevel average effects rather than city-level effects. We implement a generalized placebo method proposed by Cavallo et al. (2013) and Galiani and Quistorff (2017) to calculate p-values for the average effects of medical marijuana laws.

Let $\hat{\alpha}_{i s}$ be a difference-in-difference estimate derived from a synthetic control for city $i$ in medical marijuana state $s$. We aggregate the estimates to state level, $\bar{\alpha}_{s} \equiv$ $\frac{\sum_{i=1}^{N^{s}} \widehat{\alpha}_{i s}}{N^{s}}$, where $N^{s}$ is the number of cities state $s$. We then aggregate state-level averages to the national average, $\bar{\alpha} \equiv \frac{\sum_{s=1}^{N} \bar{\alpha}_{s}}{N}$, where $N$ is the number of medical marijuana states $(N=18)$.

Let $\hat{\gamma}_{j k}^{S}$ be an estimate for the placebo effect in city $j$ of state $k$ in the donor pool, where the placebo was implemented in the year in which the medical marijuana law in state $s$ becomes effective. As each medical marijuana state $s$ has a donor pool of around 350 to 400 cities, the total number of $\hat{\gamma}_{j k}^{s}$ across all 18 medical marijuana laws is $6,910 .{ }^{15}$ To replicate the relationship between the national average $\bar{\alpha}$ and the state-level averages $\bar{\alpha}_{s}$, we calculate the average $\hat{\gamma}_{j k}^{s}$ by state to obtain $\bar{\gamma}^{k(s)}=\frac{\sum_{j=1}^{N^{k}} \widehat{\gamma}_{j k}^{s}}{N^{k}}$, where $N^{k}$ is the number of cities in each nonmedical marijuana state $k(k=1,2, \ldots, 32)$, and then randomly select one state-level average $\bar{\gamma}^{k(s)}$ for each medical marijuana law $s$ to obtain an average placebo effect at the national level: $\bar{\gamma}=\frac{\sum_{s=1}^{N} \bar{\gamma}^{k(s)}}{N}=$

\footnotetext{
${ }^{14}$ Empirical researchers rarely acknowledge the problems caused by a small number of treatment units. Conley and Taber (2011) point out that both the point estimates and standard errors from fixed effect regressions are generally biased when the number of policy changes is small and fixed.

${ }^{15}$ Notice that the placebo sets are identical for states that passed laws in the same year. For example, the placebo sets for Oregon and Washington are identical as both states passed medical marijuana laws in 1998.
} 
$\frac{\bar{\gamma}^{k(1)}+\bar{\gamma}^{k(2)}+\ldots+\bar{\gamma}^{k(18)}}{18}$. We repeat this procedure one million times to form a placebo distribution of $\bar{\gamma} \cdot{ }^{16}$ To characterize the distribution of placebo effects and assess how the estimate $\bar{\alpha}$ ranks in that distribution, we define the one-sided and two-sided pvalues as follows:

Two-sided p-value $=\frac{\sum I(|\bar{\gamma}|>|\bar{\alpha}|)}{1,000,000}$;

One sided p-value $=\frac{\sum I(\bar{\gamma}>\bar{\alpha})}{1,000,000}$ if $\bar{\alpha}>0$;

One sided p-value $=\frac{\sum I(\bar{\gamma}<\bar{\alpha})}{1,000,000}$ if $\bar{\alpha}<0$,

where $I(\cdot)$ is an indicator function. Notice that the placebo distribution may not center around zero, and thus the one-sided p-value is not equal to half of the two-sided p-value. Placebo effects may be quite large if their control units were not matched well in the pretreatment period, which can cause p-values to be too conservative (Galiani and Quistorff 2017). Therefore, we also present p-values calculated using only control units with a root mean square percentage error (RMSPE) less than the $75^{\text {th }}$ percentile to construct the placebo distribution.

The inference for state-level averages $\bar{\alpha}_{s}$ is similar. For medical marijuana states with only one city, the inference is simply the original placebo method in Abadie, Diamond, and Hainmueller (2010). Otherwise, we characterize the placebo distribution by randomly selecting $N^{s}$ city-level placebo estimates from medical marijuana state $s$, donor pool, taking their average, $\bar{\gamma}^{s}=\frac{\sum \widehat{\gamma}_{j k}^{s}}{N^{s}}$, and repeating one million times. ${ }^{17}$ The one-sided and two-sided p-values are defined as for the national average.

\subsection{Results}

Figures 1 and 2 present graphical evidence of medical marijuana laws' effects on log violent crime rates and log property crime rates, with 0 on the $\mathrm{x}$-axis denoting the first full year of the law being effective, -1 to -7 denoting the pre-treatment period in which the synthetic control is fitted and 1 to 7 denoting the post-treatment period. To create the data in Figures 1 and 2 we first obtain the synthetic control for each medical marijuana city. Data for treated cities and for their synthetic controls are

\footnotetext{
${ }^{16}$ We randomly sample placebo states rather than calculate the average for all permutations of placebo states $k$ and medical marijuana laws $s$, as the total number of such permutations is $k^{s} \approx 10^{27}$.

${ }^{17}$ As Montana only has two cities in the sample, we use all available $\bar{\gamma}^{s}$ to form the placebo distribution as the total number of possible $\bar{\gamma}^{s}$ is less than one million.
} 
averaged to the state level and then averaged to the national level. (Each state receives equal weight.) The upper panel in each figure shows average crime rates by each year relative to treatment, the lower graph shows demeaned crime rates in which we partial out group averages.

Figure 1 shows that the synthetic violent crime rates fit the actual violent crime rates very well. The violent crime rates in the treatment and synthetic control groups are nearly identical for each year after the medical marijuana law is effective. The difference-in-difference estimate suggests only a 3.2\% decrease in violent crime using these national aggregates of violent crime reported in Figures $1 .{ }^{18}$ In Figure 2, despite a level difference between the treatments states and their synthetic controls, the property crime rates in the two groups move closely both before and after the passage of medical marijuana laws. The difference-in-difference estimate based on Figure 2 suggests only a 1.4\% increase in property crime. It is clear from Figures 1 and 2 that both violent and property crimes in the treatment group do not deviate from their synthetic controls, suggesting medical marijuana laws do not affect crime. However, as appropriate standard errors for these difference-in-difference estimates do not exist, we need to use the placebo method to conduct inference.

Tables 4 and 5 present the difference-in-difference estimates for the effects of medical marijuana laws on violent and property crime derived from synthetic control groups; we average city-level estimates to obtain individual estimates in each of the 18 medical marijuana states and then average across states to obtain the national-level estimates. Therefore, each medical marijuana state receives equal weight in Tables 4 and 5. We report the estimates for the overall effects as well as estimates for the effects in each year after the passage of medical marijuana laws (Year 0 to Year 7; Year 0 denotes the first full year of the law being effective). ${ }^{19}$ Columns (1) and (2) present one-sided and two-sided p-values based on placebo effects from all control units, and columns (3) and (4) present p-values based on placebo effects from control units below the $75^{\text {th }}$ percentile of RMSPE.

\footnotetext{
${ }^{18}$ Because the data are averaged first then differenced, the aggregate estimates reported in Figures 1 and 2 are slightly different from the average estimates reported in Tables 4 and 5 in which the data are differenced first then averaged. The aggregate estimates in Figures 1 and 2 give more weights to states passing medical marijuana laws earlier. In contrast, the average estimates in Tables 4 and 5 give equal weight to each medical marijuana state regardless of their number of post-treatment observations.

${ }^{19}$ The estimate for Year $t$ is $\hat{\alpha}_{i s}^{t}=\left(\right.$ crime $_{i s}^{t, \text { treat }}-$ crime $\left._{i s}^{t, \text { control }}\right)-\left(\overline{\text { crime }}_{i s}^{\text {before, treat }}-\overline{\text { crime }}_{i s}^{\text {before, control }}\right)$ for city $i$ in state $s$, where $t=0,1, \ldots, 7$. As in Figures 1 and 2, only states which have had an effective medical marijuana law for at least $t$ years contribute to the estimate for Year $t$.
} 
All of the estimates in Tables 4 and 5 are small, with large p-values, and are thus not statistically significant. The p-values in columns (1) - (2) and (3) - (4) are nearly identical, and none of the p-values suggest statistical significance at the conventional levels. The estimates for $M M L$ indicate an average effect of a $3.7 \%$ decrease in violent crime in Table 4 and an average effect of 1.5\% increase in property crime in Table 5. However, in column (1) (column (2)) the two-sided (one sided) pvalues show that $23 \%$ (20\%) of placebo estimates for violent crime and $41 \%$ (28\%) of placebo estimates for property crime are greater than the actual $M M L$ estimates. Therefore, there is no evidence that the estimates are drawn from a different distribution from the placebo effects. Most of the estimates for specific years are also close to zero and not statistically significant.

Figures 3 and 4 plot the distributions of the one million placebo estimates for violent and property crime based on all control units (upper graph) and based on control units of less than 75-percentile RMSPE (lower graph). While the distributions do not center at zero, they are bell-shaped and approximately normally distributed. The placebo distributions for violent crime are more dispersed and wider than the placebo distributions for property crime. To compare the magnitudes of actual estimates with placebo estimates, we plot the actual estimates as vertical lines against these placebo distributions. The actual estimates are not larger in absolute terms than a large proportion of the placebo estimates.

At the national level, the results from the synthetic control method strongly suggest medical marijuana laws do not affect crime, and they are roughly consistent with those from the state-level regression analysis.

One advantage of the synthetic control method and placebo inference is that it does not suffer the finite sample bias in fixed effects regression when the number treated units is small (see note 13). Therefore, the synthetic control method can estimate causal effects for individual treated units and thus detect heterogeneous treatment effects. We take (unweighted) averages from city-level estimates to obtain estimates in each medical marijuana state. Tables 6 and 7 present these state-level averages and their two-sided p-values. ${ }^{20}$ The medical marijuana states are ordered (left to right, upper to lower) by the year in which each state’s medical marijuana law became legally effective.

\footnotetext{
${ }^{20}$ Appendix Tables A4 and A5 present the state-level averages that are weighted by city populations. The results from Tables 6 and 7 and Appendix Tables A4 and A5 are quantitatively similar and consistent with there being little heterogeneity within states. (See also Note 11.)
} 
In Table 6, three early medical marijuana law adopters, California, Washington, and Oregon, show a $20 \%$ decrease in total violent crime rates immediately after the enactment of their laws. Except for California, we do not find violent crime rates decrease in the two other states boarding Mexico - Arizona and New Mexico - as in Gavrilova, Kamada, and Zoutman (2018). The estimated standard errors in Gavrilova, Kamada, and Zoutman (2018) likely suffered from the finite sample bias described by (Conley and Taber 2011) because there are only three treated states. Violent crime rates also appear to decrease in Connecticut and New Jersey by $9-14 \%$, though these states passed medical marijuana laws recently and thus their estimates are based on only one or three years of post-treatment data. Interestingly, while the estimates for violent crime tend to have large p-values and are not statistically significant, nearly all of the estimates show negative signs. Medical marijuana laws do not appear to be associated with increases in violent crimes. ${ }^{21}$ In Table 7, the estimate indicates a 23\% decrease in total property crime rates in California after medical marijuana law passage. However, we find no comparable decrease in property crime rates in Washington or Oregon. In fact, in Table 7, estimates for all states other than California have large p-values and are not statistically significant. There is no evidence that medical marijuana laws consistently affect property crime.

While some researchers suggest that the details of medical marijuana laws are important (Pacula, Boustead, and Hunt 2014; Pacula et al. 2015), these details do not appear to matter in the context of crime. For example, California, Oregon and Washington are the only three states showing plausible decreases in violent crime, but their laws are quite different. Only the dispensaries in California are legally protected (see Note 5), and their numbers are far greater than in Oregon and Washington. Only Oregon requires registration; California has a voluntary registration program and Washington does not have registration. As these three states are adjacent and their laws were passed at similar times, their post-law reductions in violent crime might be partly due to unobserved regional trends.

\footnotetext{
${ }^{21}$ The positive, large, and significant estimate in Montana is driven by measurement error as the data are largely missing or with extremely low reported violent crimes in the 1990s (before the passage of its medical marijuana law).
} 
Overall, we find only a little heterogeneity in the effects of medical marijuana laws as most estimates are small. ${ }^{22}$ The only notable exception is California which exhibits a significant decrease in both violent and property crime after the passage of medical marijuana law. In Figure 5 we plot the violent and property crime rates for California and its synthetic control before and after its medical marijuana law passage. The violent and property crime rates in California substantially deviate from its synthetic controls. As California passed an amendment (Senate Bill 420) in 2004 that set up statewide guidelines for marijuana provision and also grants implied legal protection for marijuana dispensaries, we also plot violent and property crime rates before and after the 2004 amendment in Appendix Figure A1; the violent crime continues to decrease after the amendment while property crime remains similar to that in the synthetic control.

In summary, the results in Tables 6 and 7 indicate that violent and property crime rates in medical marijuana states are generally similar to those of their synthetic controls. The estimates tend to be negative for violent crime and positive for property crime but they mostly have small magnitudes and large p-values and are thus not statistically significant. In Figure 6, the red lines indicate those 18 state-level estimates for medical marijuana laws reported in Table 6 and 7. Except for a few outliers, most of the state-level estimates are distributed around zero. The estimates for violent crime show more dispersion and are slightly more likely being negative than those for property crime. We also plot city-level estimates in blue bins in Figure 6. The city-level estimates are distributed near zero but tend to be negative because $40 \%$ of cities are from California which experienced substantial decreases in both violent and property crime.

In Table 8, we apply the synthetic control method to estimate the effects of medical marijuana laws on each category of crimes: murder, forcible rape, robbery, aggravated assault, burglary, larceny, and motor vehicle theft. Because an agency may report zero incidence in one or more categories, the dependent variables are crime rates per 100,000 residents without taking logarithms. As in Tables 4 and 5, we calculate difference-in-difference estimates for each medical marijuana city using their synthetic controls and average city-level estimates to the state level and then the national level.

\footnotetext{
${ }^{22}$ The aggregate figures for violent and property crime in each medical marijuana state and its synthetic control are available upon request. These figures show that violent and property crime rates in the synthetic controls move closely with the treatment group in most medical marijuana states.
} 
We also report average crime rates before the enactment of medical marijuana laws for each crime.

In Table 8, columns (1) - (4), all of the estimates for violent crimes are negative. The estimate for murder indicates a decrease of $8.5 \%$ but is statistically insignificant. ${ }^{23}$ All other estimates are small and suggest only about $4-5 \%$ decreases in forcible rape, robbery and aggravate assault. Only the estimate for robbery is marginally significant at $5 \%$ level $(p-v a l u e=0.046)$. For property crimes $($ columns $(5)-(7))$, the estimates for burglary and larceny are close to zero and statistically insignificant. However, medical marijuana laws appear to cause a sizeable increase in motor vehicle theft. The estimate is highly significant ( $\mathrm{p}$-value $=0.002)$ and indicates an $8.1 \%$ increase in motor vehicle theft. Overall, the synthetic control method finds no strong effect on crimes except for motor vehicle theft. ${ }^{24}$

\section{Discussion and Conclusion}

This paper has attempted to resolve discrepancies in the existing literature evaluating medical marijuana laws' effects on crime. We first adopted the regression approach taken by the existing literature. To minimize measurement error we used agency-level data from cities with more than 50,000 residents. To loosen the parallel trends assumption we estimated regression models controlling for city-specific polynomial time trends. To allow for heterogeneous effects we estimated regressions at both the state level and the city level.

We found that these decisions matter. The specification of the city-specific trend changes the estimated effects on violent crime, and the high weight given to California by city-level regressions results in a significant estimated effect which is otherwise negligible. As such we complemented our regression model with a synthetic control model which can further loosen the parallel trends assumption and better estimate state-

\footnotetext{
${ }^{23}$ Carefully examining the data by state indicate that the large decrease in murder is due to an outlier, the District of Columbia, which has an estimate of a decrease of 11 murders per 100,000 residents. Excluding the District of Columbia results in a statistically insignificant estimate of only 0.08 decrease in murder per 100,000 (a 1.5\% decrease) (not reported in the paper). The estimates for each crime by medical marijuana state are available upon request.

${ }^{24}$ Appendix Figures A2 and A3 show the aggregate graph for each violent and property crime. Except for motor vehicle theft, all other violent and property crimes in medical marijuana states do not substantially deviate from those in the synthetic controls, suggesting that the effect of laws on crimes are small to none. As the differences in estimates between Figures 1 and 2 and Tables 4 and 5, because of the alternative order of taking difference and averaging, the average estimates in Table 8 and the aggregate estimates reported in Appendix Figures A2 and A3 are somewhat different (for example, the estimates for motor vehicle theft). See also Note 17.
} 
specific effects. The synthetic control demonstrates that medical marijuana laws have no strong, consistent effect on violent and property crimes. The national-level estimates averaged across medical marijuana states are close to zero, as are state-specific estimates in most medical marijuana states, though California shows about a $20 \%$ reduction in both violent and property crimes.

As indicated by our opening quote, the criminalization of marijuana has always been motivated by the fear that marijuana causes criminality. As medical marijuana laws increase heavy marijuana use (Chu 2014; Wen, Hockenberry, and Cummings 2015), our null result suggests that even heavy medical marijuana use has a negligible effect on criminality. We also find no strong evidence that heavy marijuana users commit property crime to fund addictions. Our results suggest that liberalization of marijuana laws is unlikely to result in the substantial social cost from a surge in crime that some politicians clearly fear.

Nevertheless, we do not find the reduction in violent crime predicted by some medical marijuana proponents. This may be because the marijuana black market lacks the violence associated with the black markets for hard drugs (Caulkins and Pacula 2006; Reuter 2009). Alternatively, the marijuana black market may not be much affected by medical marijuana laws because the supply of marijuana remains tightly restricted following these laws, and there are few dispensaries in most states. These remaining restrictions may explain why marijuana arrests tend to increase following medical marijuana legalization (Chu 2014). Further analysis of more radical law reform - such as the recent legalization of recreational marijuana use - would better demonstrate whether eliminating the marijuana black market affects violent and property crime. 


\section{References:}

Abadie, Alberto, Susan Athey, Guido W Imbens, and Jeffrey Wooldridge. 2017. When Should You Adjust Standard Errors for Clustering? : National Bureau of Economic Research.

Abadie, Alberto, Alexis Diamond, and Jens Hainmueller. 2010. "Synthetic Control Methods for Comparative Case Studies: Estimating the Effect of California's Tobacco Control Program." Journal of the American Statistical Association no. 105 (490):493-505. doi: 10.1198/jasa.2009.ap08746. . 2011. "Synth: An R Package for Synthetic Control Methods in Comparative Case Studies." Journal of Statistical Software no. 42 (i13).

Abadie, Alberto, and Javier Gardeazabal. 2003. "The Economic Costs of Conflict: A Case Study of the Basque Country." American Economic Review no. 93 (1):113-132.

Adda, Jérôme, Brendon McConnell, and Imran Rasul. 2014. "Crime and the depenalization of cannabis possession: Evidence from a policing experiment." Journal of Political Economy no. 122 (5):1130-1202.

Akiyama, Yoshio, and Sharon K. Propheter. 2005. Methods of Data Quality Control: For Uniform Crime Reporting Programs. Criminal Justice Information Services Division, Federal Bureau of Investigation.

Alford, Catherine. 2014. How medical marijuana laws affect crime rates. mimeo University of Virginia Charlottesville, VA.

Anderson, D. Mark, Benjamin Hansen, and Daniel I. Rees. 2013. "Medical Marijuana Laws, Traffic Fatalities, and Alcohol Consumption." Journal of Law and Economics no. 56 (2):333-369.

Anderson, D. Mark, and Daniel I. Rees. 2014. "The Role of Dispensaries: The Devil is in the Details." Journal of Policy Analysis and Management no. 33 (1):235240. doi: 10.1002/pam.21733.

Anderson, D. Mark, Daniel I. Rees, and Joseph J. Sabia. 2014. "Medical Marijuana Laws and Suicides by Gender and Age." American Journal of Public Health no. 104 (12):2369-2376. doi: 10.2105/AJPH.2013.301612.

Barco, Mandalit del. 2010. "400 Marijuana Dispensaries To Close In Los Angeles." NPR, June 10.

Bennett, Trevor, Katy Holloway, and David Farrington. 2008. "The statistical association between drug misuse and crime: A meta-analysis." Aggression and Violent Behavior no. 13 (2):107-118.

Boles, Sharon M, and Karen Miotto. 2003. "Substance abuse and violence: A review of the literature." Aggression and violent behavior no. 8 (2):155-174.

Bolla, Karen I., Dana A. Eldreth, John A. Matochik, and Jean L. Cadet. 2005. "Neural substrates of faulty decision-making in abstinent marijuana users."

NeuroImage no. 26 (2):480-492. doi: http://dx.doi.org/10.1016/j.neuroimage.2005.02.012.

Braakmann, Nils, and Simon Jones. 2014. "Cannabis depenalisation, drug consumption and crime - Evidence from the 2004 cannabis declassification in the UK." Social Science \& Medicine no. 115:29-37. doi: http://dx.doi.org/10.1016/j.socscimed.2014.06.003.

Caulkins, J. P., and R. L. Pacula. 2006. "Marijuana markets: Inferences from reports by the household population." Journal of Drug Issues no. 36 (1):173-200.

Cavallo, Eduardo, Sebastian Galiani, Ilan Noy, and Juan Pantano. 2013. "Catastrophic Natural Disasters and Economic Growth." The Review of Economics and Statistics no. 95 (5):1549-1561. doi: 10.1162/REST_a_00413. 
Chang, Tom Y., and Mireille Jacobson. 2011. "Going to Pot? Medical Marijuana Dispensaries and Crime." Unpublished manuscript.

Chu, Yu-Wei Luke. 2014. "The effects of medical marijuana laws on illegal marijuana use." Journal of Health Economics no. 38:43-61. doi: http://dx.doi.org/10.1016/j.jhealeco.2014.07.003. . 2015. "Do Medical Marijuana Laws Increase Hard Drug Use?" The Journal of Law and Economics no. 58 (2):481-517.

Chu, Yu-Wei Luke, and Seth Gershenson. 2016. "High Times: The Effect of Medical Marijuana Laws on Student Time Use." IZA Discussion Papers No. 9887.

Conley, Timothy G, and Christopher R Taber. 2011. "Inference with "difference in differences" with a small number of policy changes." The Review of Economics and Statistics no. 93 (1):113-125.

Drug Enforcement Administration, (DEA). The DEA Position On Marijuana 2011. Available from https://www.dea.gov/docs/marijuana_position_2011.pdf.

Fergusson, David M., and L. John Horwood. 1997. "Early onset cannabis use and psychosocial adjustment in young adults." Addiction no. 92 (3):279-296.

Galiani, S., and B. Quistorff. 2017. "The synth_runner package: Utilities to automate synthetic control estimation using synth." Stata Journal no. 17 (4):834-849.

Gavrilova, Evelina, Takuma Kamada, and Floris Zoutman. 2018. "Is Legal Pot Crippling Mexican Drug Tra cking Organizations? The Effect of Medical Marijuana Laws on US Crime." The Economic Journal no. Forthcoming. doi: http://dx.doi.org/10.1111/ecoj.12521.

Gilman, Jodi M., John K. Kuster, Sang Lee, Myung Joo Lee, Byoung Woo Kim, Nikos Makris, Andre van der Kouwe, Anne J. Blood, and Hans C. Breiter. 2014. "Cannabis Use Is Quantitatively Associated with Nucleus Accumbens and Amygdala Abnormalities in Young Adult Recreational Users." The Journal of Neuroscience no. 34 (16):5529-5538. doi: 10.1523/jneurosci.474513.2014.

Green, Kerry M, Elaine E Doherty, Elizabeth A Stuart, and Margaret E Ensminger. 2010. "Does heavy adolescent marijuana use lead to criminal involvement in adulthood? Evidence from a multiwave longitudinal study of urban African Americans." Drug and alcohol dependence no. 112 (1):117-125.

Hasin, D. S., A. L. Sarvet, M. Cerdá, and et al. 2017. "Us adult illicit cannabis use, cannabis use disorder, and medical marijuana laws: 1991-1992 to 2012-2013." JAMA Psychiatry no. 74 (6):579-588. doi: 10.1001/jamapsychiatry.2017.0724.

Hoaken, Peter NS, and Sherry H Stewart. 2003. "Drugs of abuse and the elicitation of human aggressive behavior." Addictive behaviors no. 28 (9):1533-1554.

Huber, I. I. I. Arthur, Rebecca Newman, and Daniel LaFave. 2016. Cannabis Control and Crime: Medicinal Use, Depenalization and the War on Drugs. In The B.E. Journal of Economic Analysis \&amp; Policy.

Kepple, Nancy J, and Bridget Freisthler. 2012. "Exploring the ecological association between crime and medical marijuana dispensaries." Journal of studies on alcohol and drugs no. 73 (4):523-530.

Lynch, James P., and John P. Jarvis. 2008. "Missing Data and Imputation in the Uniform Crime Reports and the Effects on National Estimates." Journal of Contemporary Criminal Justice no. 24 (1):69-85.

Macleod, John, Rachel Oakes, Alex Copello, Ilana Crome, Matthias Egger, Mathew Hickman, Thomas Oppenkowski, Helen Stokes-Lampard, and George Davey Smith. 2004. "Psychological and social sequelae of cannabis and other illicit 
drug use by young people: a systematic review of longitudinal, general population studies." The Lancet no. 363 (9421):1568-1569.

Markowitz, Sara. 2005. "Alcohol, Drugs and Violent Crime." International Review of Law and Economics no. 25 (1):20-44. doi: http://dx.doi.org/10.1016/j.irle.2005.05.003.

Martins, Silvia S., Christine M. Mauro, Julian Santaella-Tenorio, June H. Kim, Magdalena Cerda, Katherine M. Keyes, Deborah S. Hasin, Sandro Galea, and Melanie Wall. 2016. "State-level medical marijuana laws, marijuana use and perceived availability of marijuana among the general U.S. population." Drug and Alcohol Dependence no. 169 (Supplement C):26-32. doi: https://doi.org/10.1016/j.drugalcdep.2016.10.004.

Meier, Madeline H., Avshalom Caspi, Antony Ambler, HonaLee Harrington, Renate Houts, Richard S. E. Keefe, Kay McDonald, Aimee Ward, Richie Poulton, and Terrie E. Moffitt. 2012. "Persistent cannabis users show neuropsychological decline from childhood to midlife." Proceedings of the National Academy of Sciences no. 109 (40):E2657-E2664. doi: 10.1073/pnas.1206820109.

Miczek, Klaus A, Joseph F DeBold, Margaret Haney, Jennifer Tidey, Jeffrey Vivian, and Elise M Weerts. 1994. "Alcohol, drugs of abuse, aggression, and violence." Understanding and preventing violence no. 3.

Mikos, Robert A. 2011. "A critical appraisal of the Department of Justice's new approach to medical marijuana." Stanford Law \& Policy Review no. 22 (2):633-670.

Moore, Todd M., and Gregory L. Stuart. 2005. "A review of the literature on marijuana and interpersonal violence." Aggression and Violent Behavior no. 10 (2):171-192. doi: https://doi.org/10.1016/j.avb.2003.10.002.

Morris, Robert G., Michael TenEyck, J. C. Barnes, and Tomislav V. Kovandzic. 2014. "The Effect of Medical Marijuana Laws on Crime: Evidence from State Panel Data, 1990-2006." PLoS ONE no. 9 (3):e92816. doi: 10.1371/journal.pone.0092816.

Norström, Thor, and Ingeborg Rossow. 2014. "Cannabis use and violence: Is there a link?" Scandinavian Journal of Public Health no. 42 (4):358-363. doi: doi:10.1177/1403494814525003.

Office of National Drug Control Policy. 2014. 2013 Annual Report, Arrestee Drug Abuse Monitoring Program II. Washington, DC: Executive Office of the President.

Ostrowsky, Michael K. 2011. "Does Marijuana Use Lead to Aggression and Violent Behavior?" Journal of Drug Education no. 41 (4):369-389. doi: doi:10.2190/DE.41.4.c.

Pacula, Rosalie L., Anne E. Boustead, and Priscillia Hunt. 2014. "Words Can Be Deceiving: A Review of Variation among Legally Effective Medical Marijuana Laws in the United States." Journal of Drug Policy Analysis no. Published Online: 2014-05-21. doi: 10.1515/jdpa-2014-0001.

Pacula, Rosalie L., David Powell, Paul Heaton, and Eric L. Sevigny. 2015. "Assessing the Effects of Medical Marijuana Laws on Marijuana Use: The Devil is in the Details." Journal of Policy Analysis and Management no. 34 (1):7-31. doi: 10.1002/pam.21804.

Pacula, Rosalie Liccardo, and Beau Kilmer. 2003. Marijuana and crime: Is there a connection beyond prohibition? : National bureau of economic research.

Powell, David, Rosalie Liccardo Pacula, and Mireille Jacobs. 2015. "Do Medical Marijuana Laws Reduce Addiction and Deaths Related to Pain Killers?" 
RAND Corporation, WR-1130, http://www.rand.org/pubs/working_papers/WR1130.html.

ProCon.org. 2016. Number of Legal Medical Marijuana Patients [ ], March 1, 2016 2016 [cited April 2 2016]. Available from https://medicalmarijuana.procon.org/view.resource.php?resourceID=006941. . 2017. 29 Legal Medical Marijuana States and DC, 11/30/2017 2017 [cited December 30 2017]. Available from http://medicalmarijuana.procon.org/view.resource.php?resourceID=000881.

Raver, Sylvina M., Sarah P. Haughwout, and Asaf Keller. 2013. "Adolescent Cannabinoid Exposure Permanently Suppresses Cortical Oscillations in Adult Mice." Neuropsychopharmacology no. 38 (12):2338-2347. doi: 10.1038/npp.2013.164.

Reuter, Peter. 2009. "Systemic violence in drug markets." Crime, Law and Social Change no. 52 (3):275-284.

Sabia, Joseph J., Jeffrey Swigert, and Timothy Young. 2017. "The Effect of Medical Marijuana Laws on Body Weight." Health Economics no. 26 (1):6-34. doi: 10.1002/hec.3267.

Sarvet, Aaron L., Melanie M. Wall, David S. Fink, Emily Greene, Aline Le, Anne E. Boustead, Rosalie Liccardo Pacula, Katherine M. Keyes, Magdalena Cerdá, Sandro Galea, and Deborah S. Hasin. 2018. "Medical marijuana laws and adolescent marijuana use in the United States: a systematic review and metaanalysis." Addiction no. Forthcoming.

Solon, Gary, Steven J. Haider, and Jeffrey M. Wooldridge. 2015. "What Are We Weighting For?" Journal of Human Resources no. 50 (2):301-316. doi: 10.3368/jhr.50.2.301.

Volkow , Nora D., Ruben D. Baler, Wilson M. Compton , and Susan R.B. Weiss 2014. "Adverse Health Effects of Marijuana Use." New England Journal of Medicine no. 370 (23):2219-2227. doi: doi:10.1056/NEJMra1402309.

Wen, Hefei, Jason M. Hockenberry, and Janet R. Cummings. 2015. "The effect of medical marijuana laws on adolescent and adult use of marijuana, alcohol, and other substances." Journal of Health Economics no. 42:64-80. doi: http://dx.doi.org/10.1016/j.jhealeco.2015.03.007. 
Table 1: State Medical Marijuana Laws as of 2016

\begin{tabular}{cc|cc}
\hline State & Date Effective & State & Date Effective \\
\hline Alaska & $03 / 04 / 1999$ & Minnesota & $05 / 30 / 2014$ \\
Arizona & $04 / 14 / 2011$ & Montana & $11 / 02 / 2004$ \\
California & $11 / 06 / 1996$ & Nevada & $10 / 01 / 2001$ \\
Colorado & $06 / 01 / 2001$ & New Hampshire & $07 / 23 / 2013$ \\
Connecticut & $10 / 01 / 2012$ & New Jersey & $06 / 01 / 2010$ \\
District of Columbia & $07 / 27 / 2010$ & New Mexico & $07 / 01 / 2007$ \\
Delaware & $07 / 01 / 2011$ & New York & $07 / 05 / 2014$ \\
Florida & $01 / 03 / 2017$ & North Dakota & $04 / 18 / 2017$ \\
Hawaii & $12 / 28 / 2000$ & Ohio & $09 / 08 / 2016$ \\
Illinois & $01 / 01 / 2014$ & Oregon & $12 / 03 / 1998$ \\
Maine & $12 / 22 / 1999$ & Pennsylvania & $04 / 17 / 2016$ \\
Maryland & $06 / 01 / 2014$ & Rhode Island & $01 / 03 / 2006$ \\
Massachusetts & $01 / 01 / 2013$ & Vermont & $07 / 01 / 2004$ \\
Michigan & $12 / 04 / 2008$ & Washington & $11 / 03 / 1998$ \\
\hline
\end{tabular}

Only states that passed laws by 1 January 2013 are coded as medical marijuana states in the paper. The laws in Minnesota, New York, Ohio, and Pennsylvania do not allow smokable marijuana and exclude dry leaf or plant form. See ProCon.org (2016a) for legal documents and details of laws. 


\section{Table 2: Regression Estimates of the Effects of Medical Marijuana Laws on Violent}

Crime

\begin{tabular}{|c|c|c|c|c|c|c|c|c|c|}
\hline & (1) & (2) & (3) & (4) & (5) & (6) & (7) & (8) & (9) \\
\hline & \multicolumn{3}{|c|}{ City Level } & \multicolumn{3}{|c|}{ City Level (No California) } & \multicolumn{3}{|c|}{ State Level } \\
\hline$M M L$ & $\begin{array}{l}-0.014 \\
(0.029)\end{array}$ & $\begin{array}{c}-0.047 * * \\
(0.020)\end{array}$ & $\begin{array}{l}-0.046 \\
(0.034)\end{array}$ & $\begin{array}{c}0.027 \\
(0.024)\end{array}$ & $\begin{array}{c}-0.017 \\
(0.016)\end{array}$ & $\begin{array}{c}0.011 \\
(0.029)\end{array}$ & $\begin{array}{c}0.006 \\
(0.032)\end{array}$ & $\begin{array}{l}-0.032 \\
(0.033)\end{array}$ & $\begin{array}{l}-0.086 \\
(0.090)\end{array}$ \\
\hline Time Trends & Linear & Quadratic & Cubic & Linear & Quadratic & Cubic & Linear & Quadratic & Cubic \\
\hline Observations & 18,607 & 18,607 & 18,607 & 15,080 & 15,080 & 15,080 & 1,287 & 1,287 & 1,287 \\
\hline No. of City & 825 & 825 & 825 & 648 & 648 & 648 & - & - & - \\
\hline No. of State & 50 & 50 & 50 & 49 & 49 & 49 & 50 & 50 & 50 \\
\hline
\end{tabular}

Table 2 lists the estimated effects of medical marijuana laws on log violent crime rates, calculated using linear regressions. All specifications control for city (or state) and year fixed effects, log city (state) populations, log city (state) police officer rates, dummy variables for marijuana decriminalization and legalization, and log state unemployment rates. Robust standard errors allowing within-state clustering are reported in parentheses. ${ }^{* * *} \mathrm{p}<0.01,{ }^{* *} \mathrm{p}<0.05,{ }^{*} \mathrm{p}<0.1$. 
Table 3: Regression Estimates of the Effects of Medical Marijuana Laws on

Property Crime

\begin{tabular}{|c|c|c|c|c|c|c|c|c|c|}
\hline & (1) & (2) & (3) & (4) & (5) & (6) & (7) & (8) & (9) \\
\hline & \multicolumn{3}{|c|}{ City Level } & \multicolumn{3}{|c|}{ City Level (No California) } & \multicolumn{3}{|c|}{ State Level } \\
\hline$M M L$ & $\begin{array}{l}-0.032 \\
(0.055)\end{array}$ & $\begin{array}{l}-0.040 \\
(0.046)\end{array}$ & $\begin{array}{l}-0.063 \\
(0.054)\end{array}$ & $\begin{array}{c}0.062 * * * \\
(0.018)\end{array}$ & $\begin{array}{c}0.038 * * \\
(0.018)\end{array}$ & $\begin{array}{c}0.040 \\
(0.024)\end{array}$ & $\begin{array}{c}0.027 \\
(0.028)\end{array}$ & $\begin{array}{c}0.027 \\
(0.028)\end{array}$ & $\begin{array}{c}0.014 \\
(0.035)\end{array}$ \\
\hline Time Trends & Linear & Quadratic & Cubic & Linear & Quadratic & Cubic & Linear & Quadratic & Cubic \\
\hline Observations & 18,607 & 18,607 & 18,607 & 15,080 & 15,080 & 15,080 & 1,287 & 1,287 & 1,287 \\
\hline No. of cities & 825 & 825 & 825 & 648 & 648 & 648 & - & - & - \\
\hline No. of states & 50 & 50 & 50 & 49 & 49 & 49 & 50 & 50 & 50 \\
\hline
\end{tabular}

Table 3 lists the estimated effects of medical marijuana laws on log property crime rates, calculated using linear regressions. All specifications control for city (or state) and year fixed effects, log city (state) populations, log city (state) police officer rates, dummy variables for marijuana decriminalization and legalization, and log state unemployment rates. Robust standard errors allowing withinstate clustering are reported in parentheses. ${ }^{* * *} \mathrm{p}<0.01,{ }^{* *} \mathrm{p}<0.05,{ }^{*} \mathrm{p}<0.1$. 


\section{Table 4: Synthetic Control Estimates of the Effects of Medical Marijuana}

Laws on Violent Crime

\begin{tabular}{|c|c|c|c|c|c|}
\hline & $(1)$ & $(2)$ & (3) & (4) & $(5)$ \\
\hline & Estimate & P-value usi & Il Placebos & $\begin{array}{r}\text { P-value } \\
\text { with } 75 \% \mathrm{~s}\end{array}$ & $\begin{array}{l}\text { placebos } \\
\text { est RMSP }\end{array}$ \\
\hline & & 2-sided & 1-sided & 2-sided & 1-sided \\
\hline Overall effect & -0.037 & 0.234 & 0.200 & 0.292 & 0.267 \\
\hline Year 0 & -0.024 & 0.420 & 0.393 & 0.496 & 0.482 \\
\hline Year 1 & -0.039 & 0.217 & 0.182 & 0.250 & 0.223 \\
\hline Year 2 & -0.036 & 0.344 & 0.250 & 0.381 & 0.287 \\
\hline Year 3 & -0.030 & 0.493 & 0.212 & 0.489 & 0.214 \\
\hline Year 4 & -0.018 & 0.684 & 0.344 & 0.715 & 0.403 \\
\hline Year 5 & -0.045 & 0.384 & 0.129 & 0.425 & 0.177 \\
\hline Year 6 & -0.002 & 0.973 & 0.377 & 0.972 & 0.402 \\
\hline Year 7 & -0.047 & 0.466 & 0.228 & 0.448 & 0.234 \\
\hline No. of MML states & & & 18 & & \\
\hline
\end{tabular}

Column 1 of Table 4 lists average differences between the log violent crime rates in states with medical marijuana laws and those of their synthetic controls, either over all years after the law was implemented (in row 1) or in particular years. Other columns list p-values calculated using placebo estimates. The 1-sided p-values are the left-tail p-values when the estimate is positive and are the right-tail p-values when the estimate is negative. 


\section{Table 5: Synthetic Control Estimates of the Effects of Medical Marijuana}

Laws on Property Crime

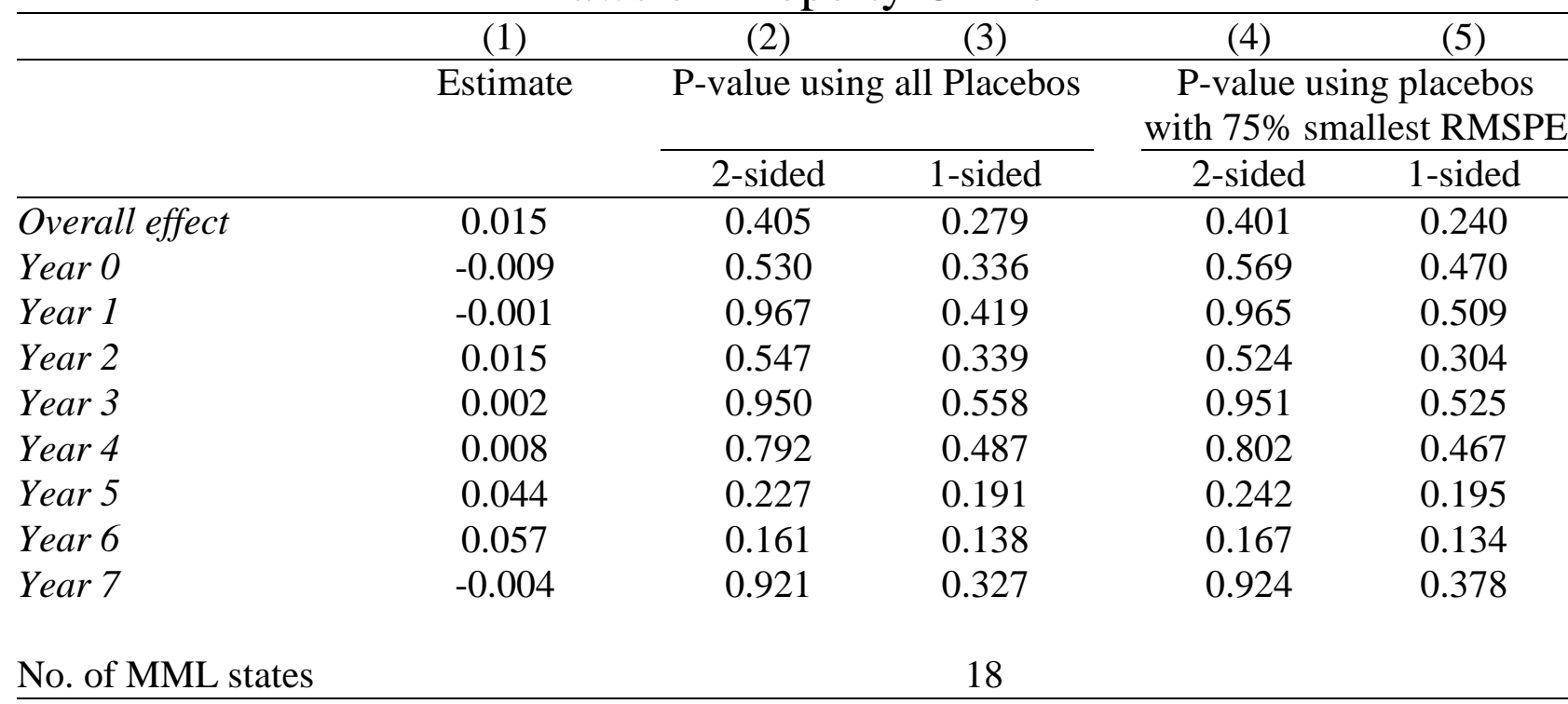

Column 1 of Table 5 lists average differences between the log property crime rates in states with medical marijuana laws and those of their synthetic controls, either over all years after the law was implemented (in row 1) or in particular years. Other columns list p-values calculated using placebo estimates. The 1-sided p-values are the left-tail p-values when the estimate is positive and are the right-tail p-values when the estimate is negative. 


\section{Table 6: Synthetic Control Estimates of the Effects of Medical Marijuana Laws on Violent Crime by State}

\begin{tabular}{lcccccc}
\hline & California & Washington & Oregon & Alaska & Maine & Hawaii \\
\cline { 2 - 7 } MML & $-0.193^{* * *}$ & $-0.212^{* * *}$ & $-0.197^{* *}$ & -0.046 & -0.112 & 0.193 \\
P-value & 0.000 & 0.004 & 0.021 & 0.852 & 0.669 & 0.381 \\
No. of citie & 127 & 15 & 11 & 1 & 1 & 1 \\
\hline & & & & & & \\
& Colorado & Nevada & Montana & Rhode Island New Mexico & Michigan \\
\cline { 2 - 7 } MML & 0.027 & -0.013 & $0.354^{*}$ & -0.056 & -0.019 & -0.027 \\
P-value & 0.713 & 0.911 & 0.087 & 0.664 & 0.850 & 0.746 \\
No. of cities & 13 & 5 & 2 & 5 & 4 & 32 \\
\hline & & & & & & \\
MML & D.C. & New Jersey & Arizona & Delaware & Connecticut & Massachusetts \\
\cline { 2 - 7 } P-value & 0.058 & $-0.090^{* * *}$ & -0.028 & -0.086 & $-0.142^{*}$ & -0.086 \\
No. of cities & 0.640 & 0.006 & 0.693 & 0.484 & 0.098 & 0.534 \\
\hline
\end{tabular}

Table 6 lists state average differences between the log violent crime rates of cities with medical marijuana laws and those of their synthetic controls. The p-values reported in the table are calculated using placebo estimates and are twosided. The order of states is based on the year in which each state's medical marijuana law became legally effective. *** $\mathrm{p}<0.01,{ }^{* *} \mathrm{p}<0.05,{ }^{*} \mathrm{p}<0.1$. 


\section{Table 7: Synthetic Control Estimates of the Effects of Medical Marijuana Laws on Property Crime by State}

\begin{tabular}{lcccccc}
\hline & California & Washington & Oregon & Alaska & Maine & Hawaii \\
\cline { 2 - 7 } MML & $-0.229 * * *$ & 0.043 & 0.009 & 0.009 & 0.113 & 0.015 \\
P-value & 0.000 & 0.356 & 0.864 & 0.955 & 0.524 & 0.936 \\
No. of cities & 127 & 15 & 11 & 1 & 1 & 1 \\
\hline & & & & & & \\
& Colorado & Nevada & Montana & Rhode Island New Mexico & Michigan \\
\cline { 2 - 7 } MML & 0.069 & 0.054 & -0.067 & 0.063 & 0.112 & -0.017 \\
P-value & 0.126 & 0.433 & 0.536 & 0.443 & 0.197 & 0.516 \\
No. of cities & 13 & 5 & 2 & 5 & 4 & 32 \\
\hline & & & & & & \\
MML & D.C. & New Jersey & Arizona & Delaware & Connecticut Massachusetts \\
\cline { 2 - 7 } P-value & 0.084 & -0.045 & 0.000 & 0.071 & 0.003 & -0.009 \\
No. of cities & 0.446 & 0.103 & 0.990 & 0.452 & 0.911 & 0.724 \\
\hline
\end{tabular}

Table 7 lists state average differences between the log violent crime rates of cities with medical marijuana laws and those of their synthetic controls. The p-values reported in the table are calculated using placebo estimates and are twosided. The order of states is based on the year in which each state's medical marijuana law became legally effective. ${ }^{* * *} \mathrm{p}<0.01,{ }^{* *} \mathrm{p}<0.05,{ }^{*} \mathrm{p}<0.1$. 


\section{Table 8: Synthetic Control Estimates of the Effects of Medical Marijuana Laws on Specific Crime Rates}

\begin{tabular}{lccccccc}
\hline & Murder & Rape & Robbery & Assault & Burglary & Larceny & Auto Theft \\
\cline { 2 - 8 } MML & -0.69 & 2.11 & $-10.01^{* *}$ & -88.57 & 12.18 & -19.45 & $46.72 * * *$ \\
P-value & 0.126 & 0.552 & 0.046 & 0.166 & 0.687 & 0.772 & 0.002 \\
Pre-MML Mean & 8.12 & 42.48 & 224.86 & 1764.90 & 945.30 & 3397.42 & 575.17 \\
No. of MML states & 18 & 18 & 18 & 18 & 18 & 18 & 18 \\
\hline
\end{tabular}

Table 8 lists differences between the crime rates in states with medical marijuana laws and those of their synthetic controls, for particular classes of crime. The p-values reported in the table are calculated using placebo estimates and are two-sided. ${ }^{* * *} \mathrm{p}<0.01,{ }^{* *} \mathrm{p}<0.05,{ }^{*} \mathrm{p}<0.1$. 


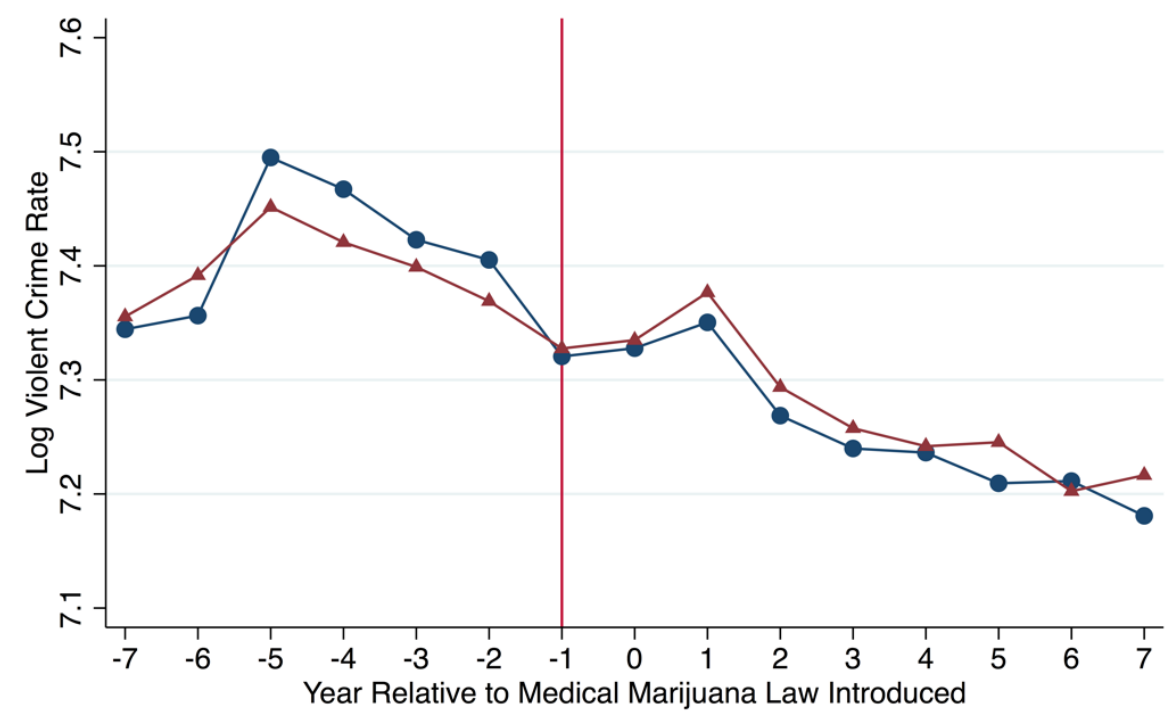

$\longrightarrow$ Treatment $\longrightarrow$ Synthetic Control

Difference-in-difference estimate: -0.032

\section{Panel A: Raw Log Crime Rates}

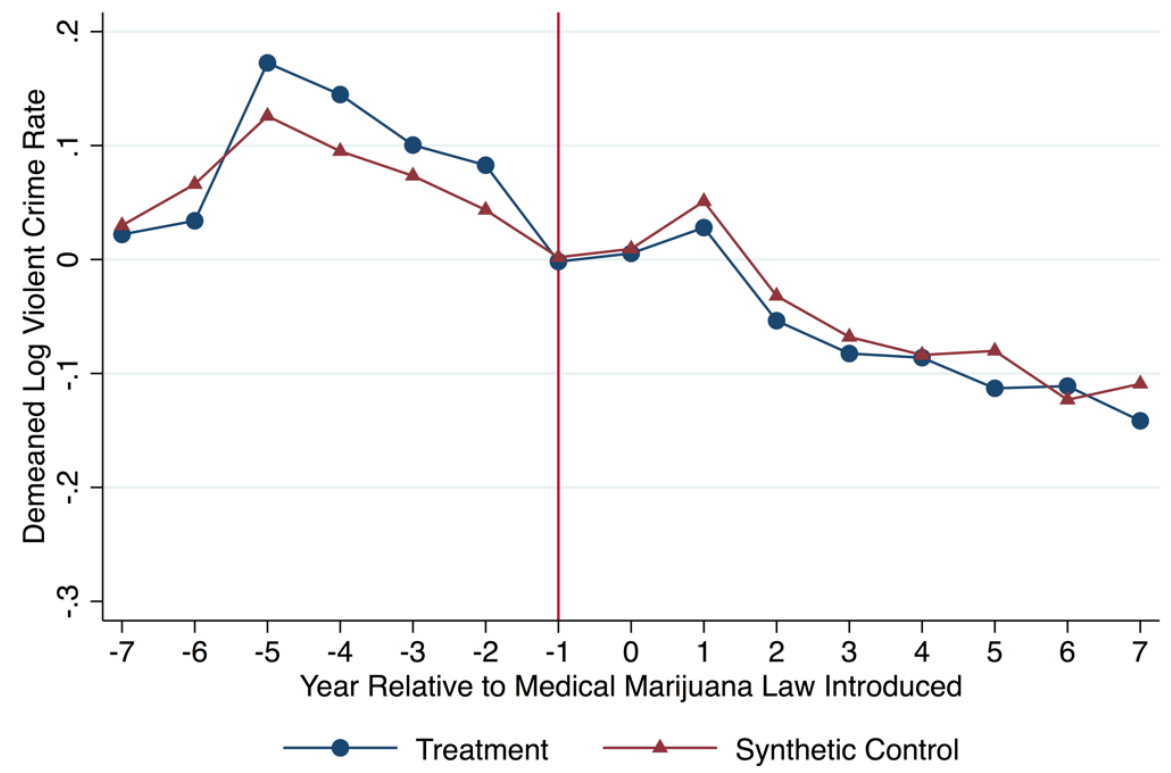

Difference-in-difference estimate: -0.032

Panel B: Demeaned Log Crime Rates

\section{Figure 1: Log Violent Crime Rates Before and After the Passage of Medical Marijuana Laws}

Figure 1 displays mean log violent crime rates per 100,000 residents across states which implemented medical marijuana laws and across their synthetic controls. The top panel presents raw log crime rates whereas the log crime rates in the second panel are demeaned within each group. 


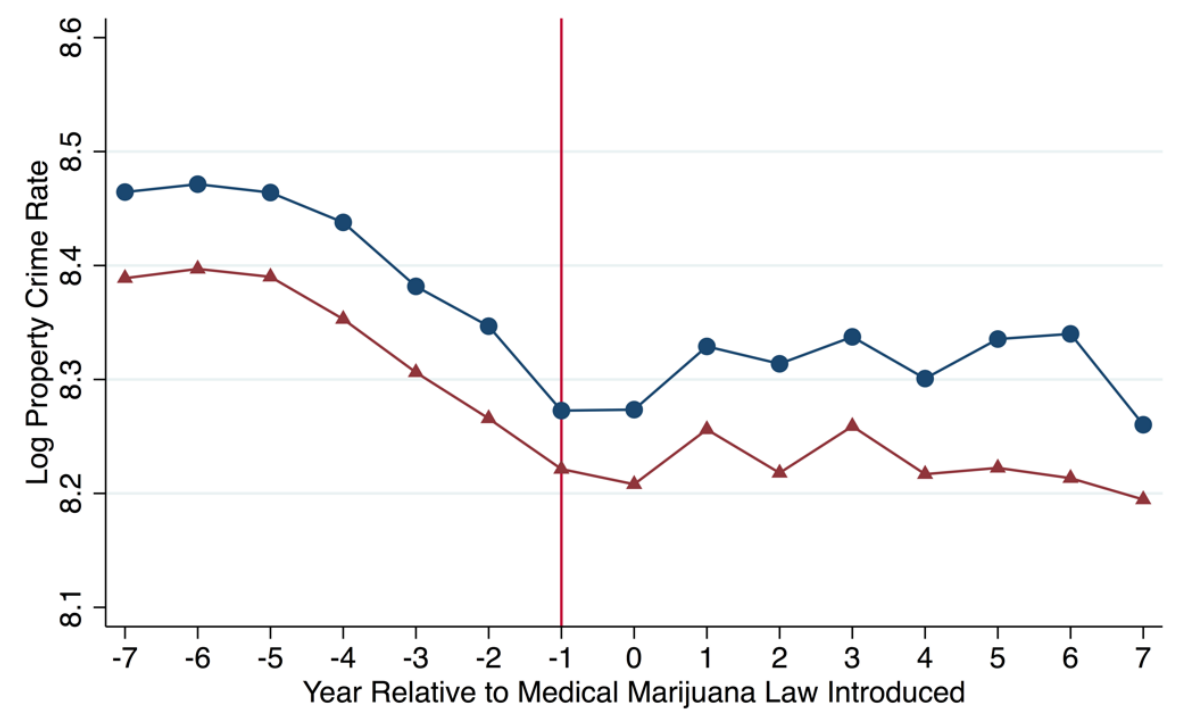

$\longrightarrow$ Treatment $\longrightarrow$ Synthetic Control

Difference-in-difference estimate: 0.014

\section{Panel A: Raw Log Crime Rates}

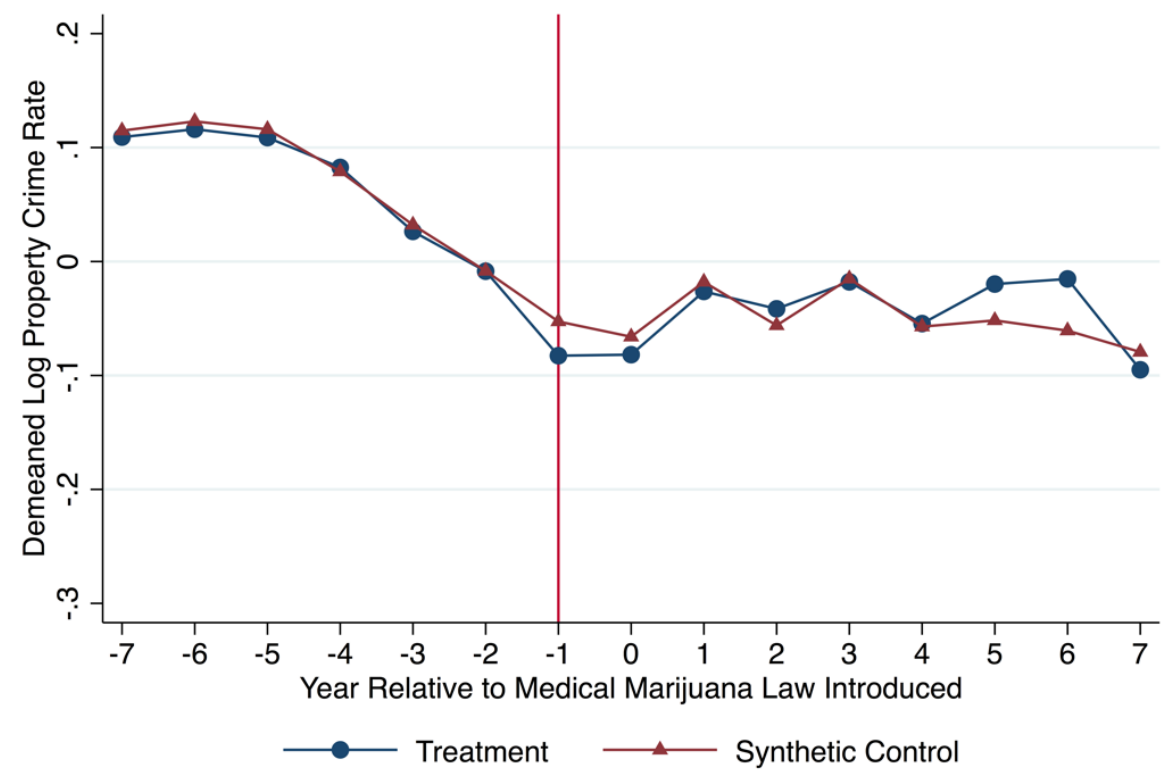

Difference-in-difference estimate: 0.014

Panel B: Demeaned Log Crime Rates

\section{Figure 2: Log Property Crime Rates Before and After the Passage of Medical Marijuana Laws}

Figure 2 displays mean log property crime rates per 100,000 residents across states which implemented medical marijuana laws and across their synthetic controls. The top panel presents raw log crime rates whereas the log crime rates in the second panel are demeaned within each group. 


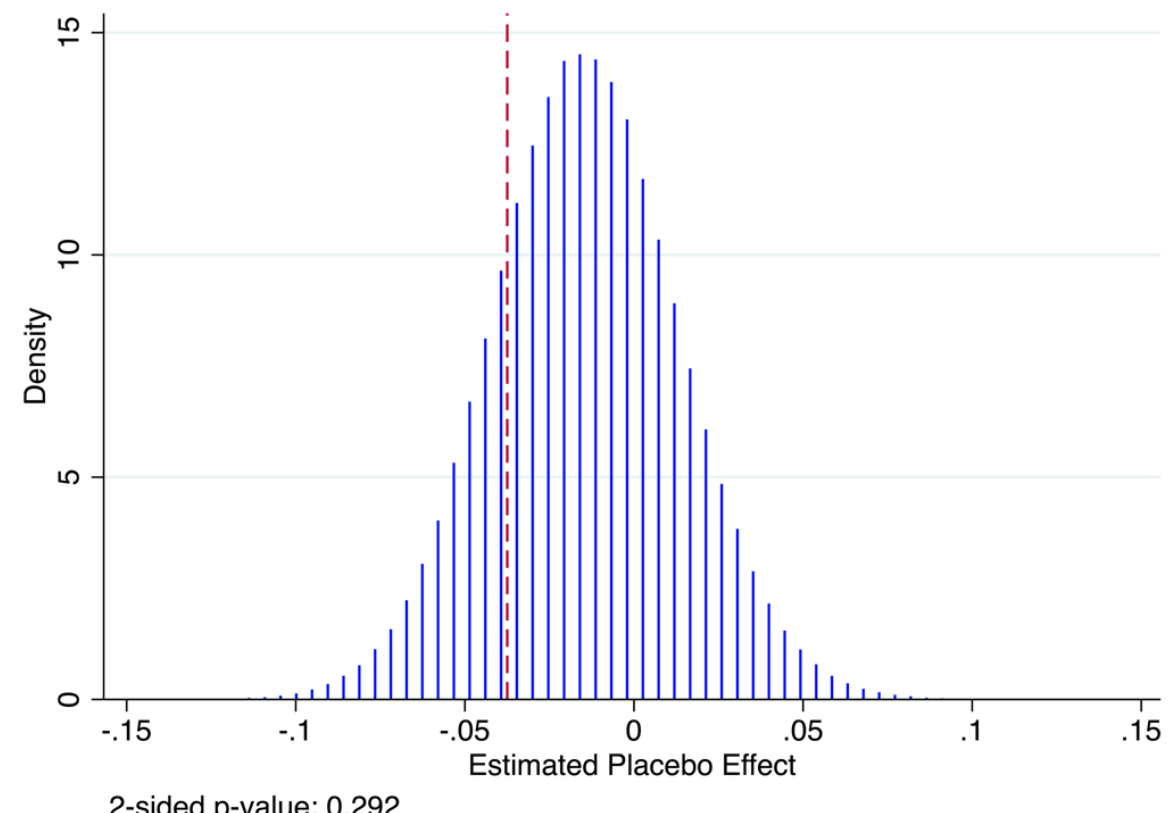

Panel A: All Placebo Estimates

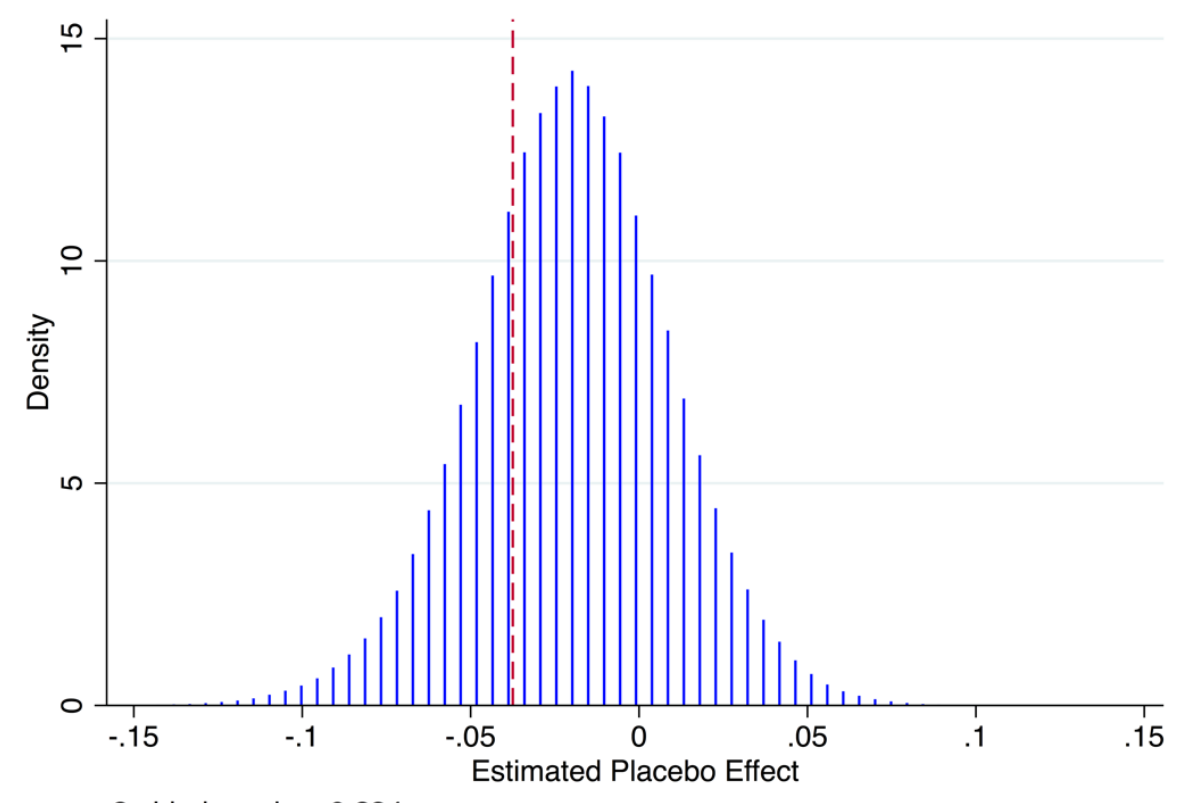

2-sided p-value: 0.234

Panel B: Best-fit Placebo Estimates

\section{Figure 3: Distribution of Placebo Effects on Log Violent Crime Rates}

The blue lines in Figure 3 represent histograms of placebo estimates of medical marijuana laws' effect on log violent crime rates, whereas the red line represents the actual estimate. In Panel A, all placebos are used, whereas in Panel B only the 75\% of placebos with the least RMSPE are used. 2-sided p-values are calculated using these placebo estimates. 


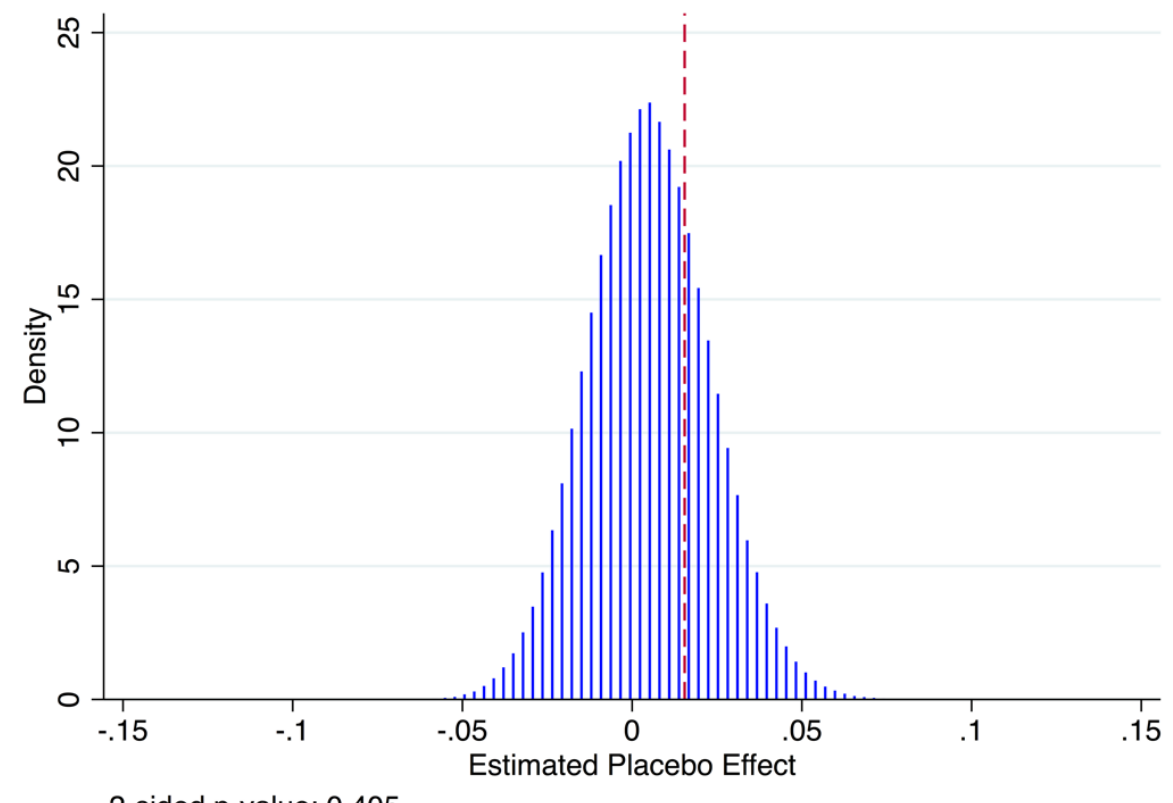

2-sided p-value: 0.405

\section{Panel A: All Placebo Estimates}

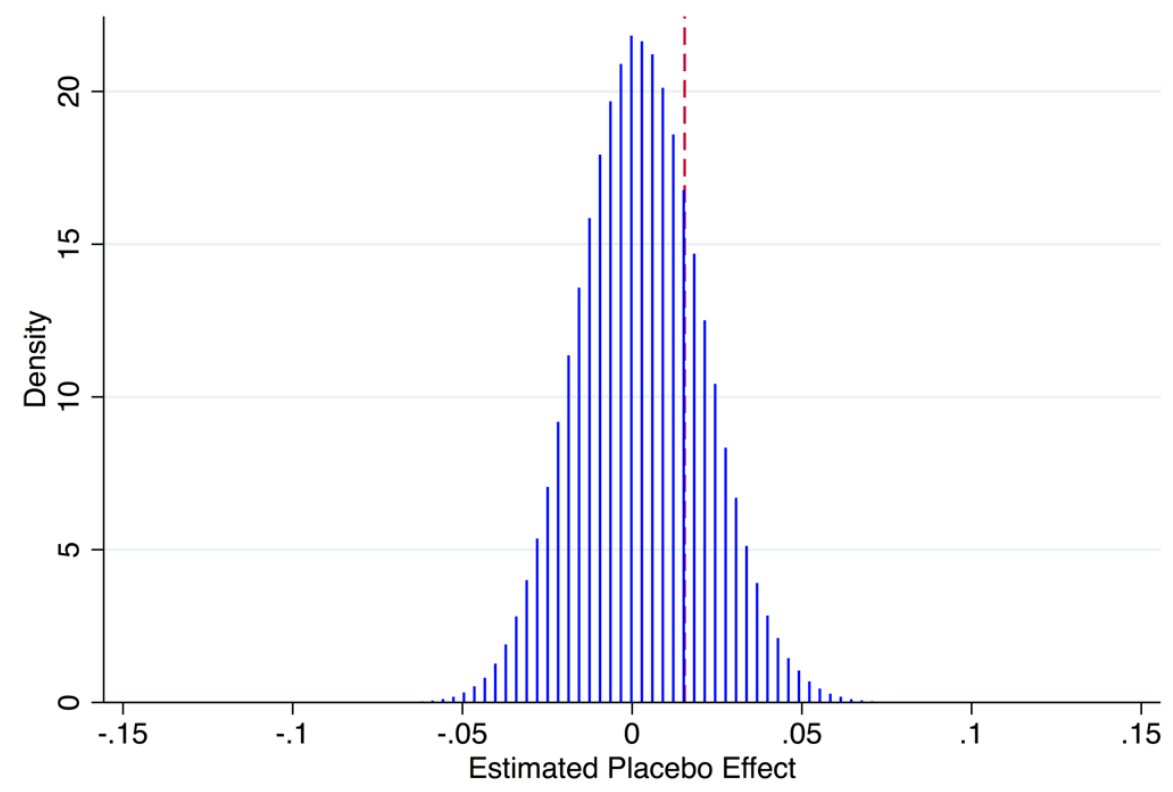

2-sided p-value: 0.401

Panel B: Best-fit Placebo Estimates

\section{Figure 4: Distribution of Placebo Effects on Log Property Crime Rates}

The blue lines in Figure 4 represent histograms of placebo estimates of medical marijuana laws' effect on log property crime rates, whereas the red line represents the actual estimate. In Panel A, all placebos are used, whereas in Panel B only the 75\% of placebos with the least RMSPE are used. 2-sided p-values are calculated using these placebo estimates. 


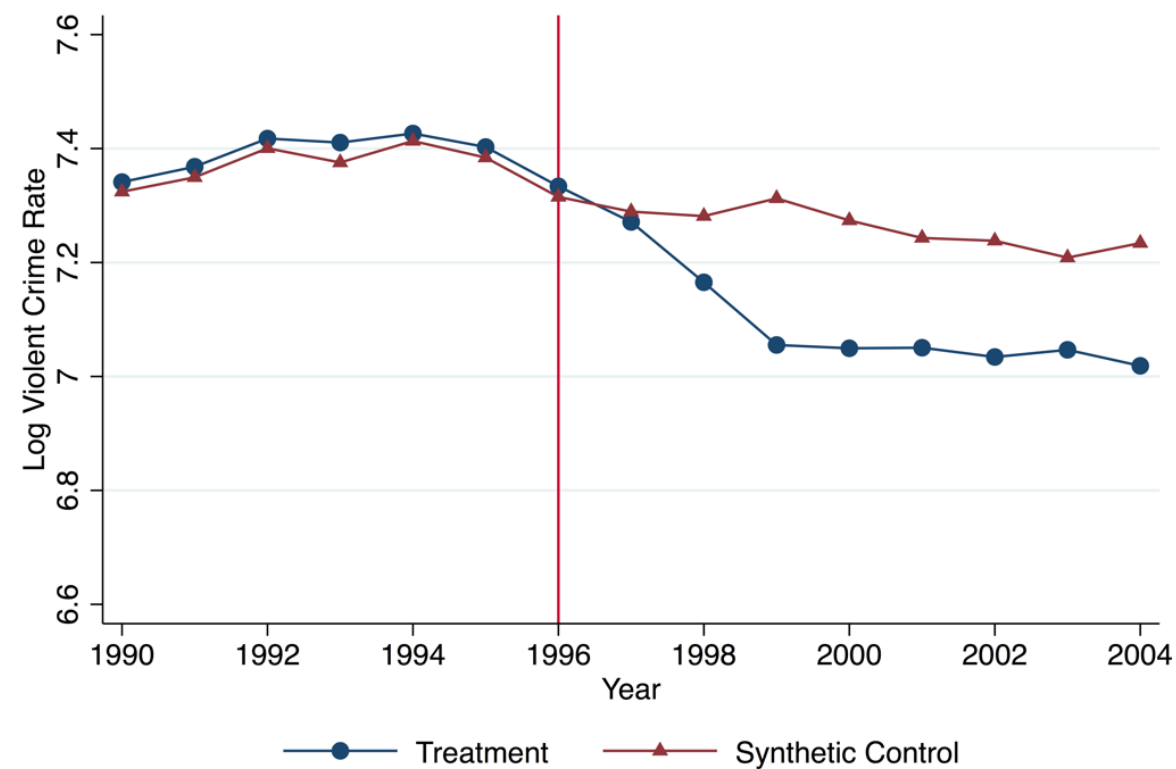

Difference-in-difference estimate: -0.193

Panel A: Violent Crime

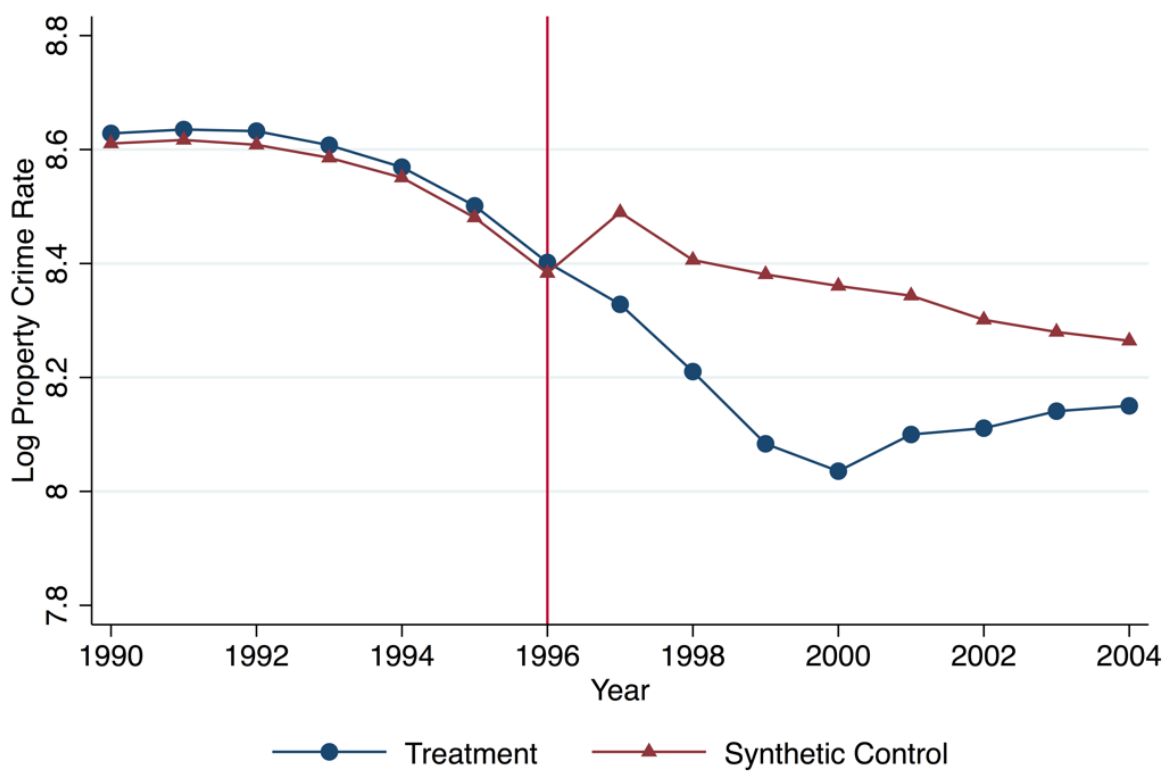

Difference-in-difference estimate: -0.228

\section{Panel B: Property Crime}

\section{Figure 5: Log Violent and Property Crime Rates Before and After the Passage of California's Medical Marijuana Law}

Figure 6 displays mean log crime rates per 100,000 residents for California and its synthetic control. The top panel presents log violent crime rates whereas the bottom presents log property crime rates. 


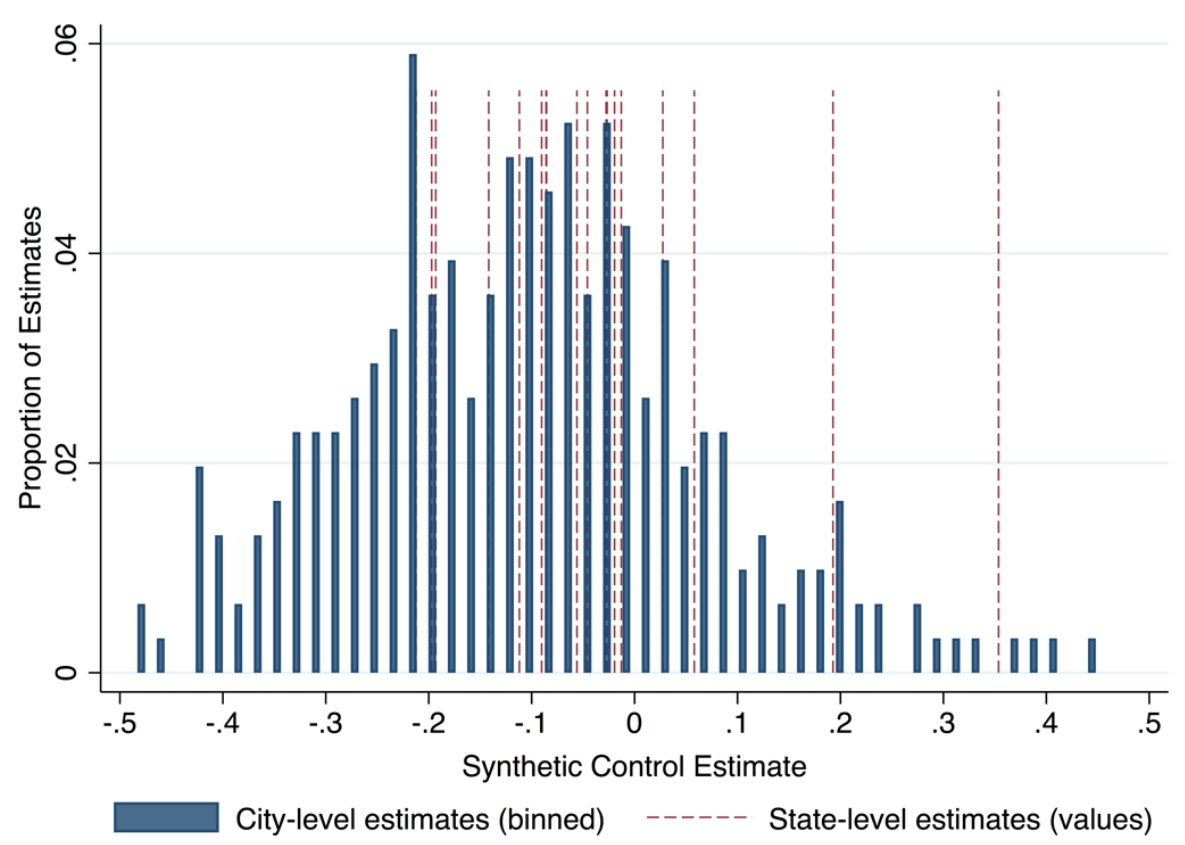

\section{Panel A: Violent Crime}

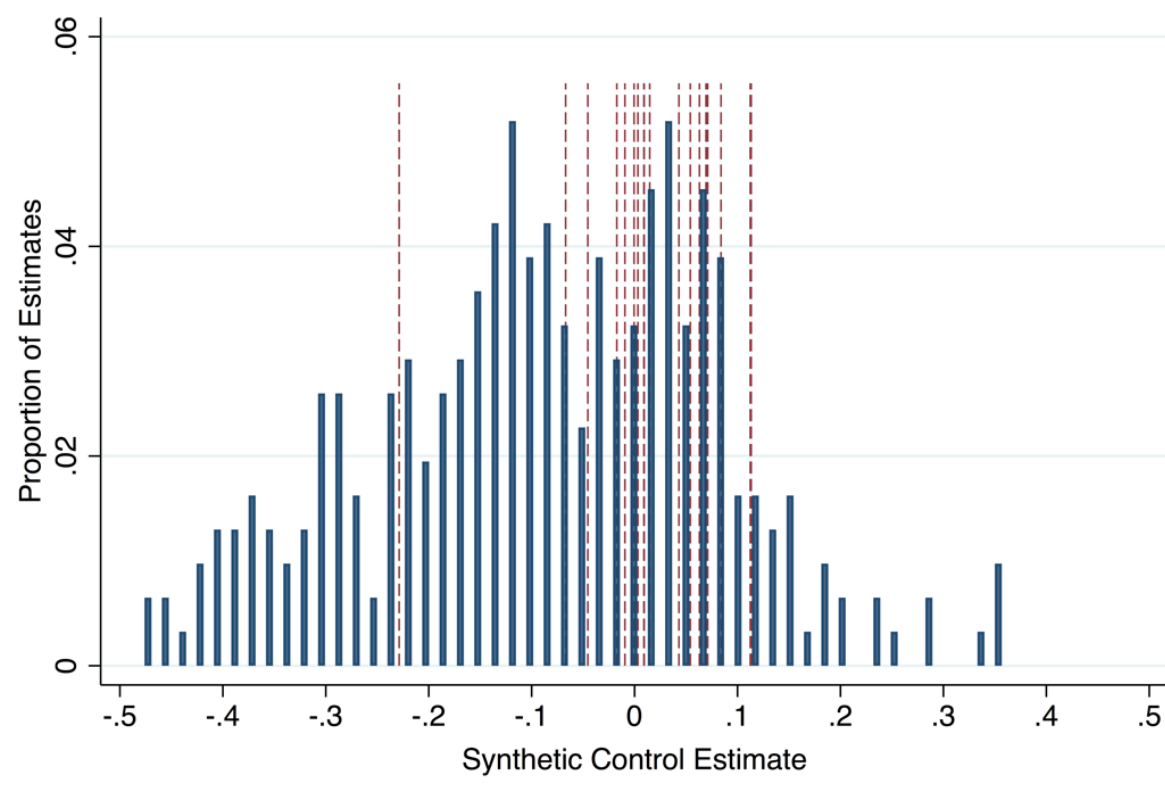

City-level estimates (binned)

State-level estimates (values)

Panel B: Property Crime

Figure 6: City- and State-specific Estimates

Figure 6 displays histograms of city-specific synthetic control estimates and the values of the state-specific estimates. 10 cities are excluded from Panel A due to being outliers 7 cities are excluded from Panel B. 
Appendix Table A1: Summary Statistics

\begin{tabular}{|c|c|c|}
\hline & $\begin{array}{c}\text { States with Medical } \\
\text { Marijuana Laws }\end{array}$ & $\begin{array}{l}\text { States without Medical } \\
\text { Marijuana Laws }\end{array}$ \\
\hline \multirow{2}{*}{ Violent Crime } & 1565.9 & 1975.5 \\
\hline & (1065.4) & (1284.1) \\
\hline \multirow{2}{*}{ Property Crime } & 4342.8 & 5196.6 \\
\hline & (2108.8) & $(2455.4)$ \\
\hline \multirow{2}{*}{ Murder } & 5.7 & 7.4 \\
\hline & $(8.4)$ & (15.4) \\
\hline \multirow{2}{*}{ Rape } & 33.4 & 41.0 \\
\hline & (26.9) & (32.1) \\
\hline \multirow{2}{*}{ Robbery } & 198.2 & 203.8 \\
\hline & $(240.3)$ & (213.5) \\
\hline \multirow{2}{*}{ Assault } & 1328.5 & 1723.3 \\
\hline & (893.1) & (1134.6) \\
\hline \multirow{2}{*}{ Burglary } & 915.1 & 1119.9 \\
\hline & $(562.1)$ & (703.3) \\
\hline \multirow{2}{*}{ Larceny } & 2791.5 & 3626.8 \\
\hline & (1407.3) & $(1605.2)$ \\
\hline \multirow{2}{*}{ Auto Theft } & 636.2 & 449.8 \\
\hline & (536.3) & $(411.4)$ \\
\hline Observations & 8,378 & 10,229 \\
\hline No. of cities & 380 & 445 \\
\hline No. of states & 18 & 32 \\
\hline
\end{tabular}

Cells contain mean crime rates per 100,000 city residents, with standard deviations in parentheses, across our analytic sample. 


\section{Appendix Table A2: Dynamic Effects of Medical Marijuana Laws on Violent}

Crime

\begin{tabular}{|c|c|c|c|c|c|c|}
\hline & (1) & (2) & (3) & (4) & (5) & (6) \\
\hline & \multicolumn{3}{|c|}{ All cities } & \multicolumn{3}{|c|}{ Without California } \\
\hline Year -5 & $\begin{array}{c}0.045 * * \\
(0.022)\end{array}$ & $\begin{array}{c}0.025 \\
(0.036)\end{array}$ & $\begin{array}{c}0.021 \\
(0.024)\end{array}$ & $\begin{array}{c}0.052 \\
(0.033)\end{array}$ & $\begin{array}{c}0.009 \\
(0.041)\end{array}$ & $\begin{array}{c}0.014 \\
(0.023)\end{array}$ \\
\hline Year -4 & $\begin{array}{c}0.065 * * * \\
(0.019)\end{array}$ & $\begin{array}{c}0.048 \\
(0.042)\end{array}$ & $\begin{array}{c}0.045 \\
(0.030)\end{array}$ & $\begin{array}{c}0.074 * * \\
(0.035)\end{array}$ & $\begin{array}{c}0.027 \\
(0.053)\end{array}$ & $\begin{array}{c}0.028 \\
(0.032)\end{array}$ \\
\hline Year -3 & $\begin{array}{c}0.058 * * * \\
(0.019)\end{array}$ & $\begin{array}{c}0.034 \\
(0.047)\end{array}$ & $\begin{array}{c}0.035 \\
(0.031)\end{array}$ & $\begin{array}{l}0.072 * \\
(0.038)\end{array}$ & $\begin{array}{c}0.006 \\
(0.056)\end{array}$ & $\begin{array}{c}0.021 \\
(0.034)\end{array}$ \\
\hline Year -2 & $\begin{array}{c}0.085^{* * *} \\
(0.021)\end{array}$ & $\begin{array}{c}0.051 \\
(0.056)\end{array}$ & $\begin{array}{c}0.064 \\
(0.041)\end{array}$ & $\begin{array}{c}0.094 * * \\
(0.041)\end{array}$ & $\begin{array}{c}0.008 \\
(0.061)\end{array}$ & $\begin{array}{c}0.043 \\
(0.051)\end{array}$ \\
\hline Year -1 & $\begin{array}{c}0.068 * * * \\
(0.024)\end{array}$ & $\begin{array}{c}0.028 \\
(0.064)\end{array}$ & $\begin{array}{c}0.053 \\
(0.053)\end{array}$ & $\begin{array}{c}0.063 \\
(0.049)\end{array}$ & $\begin{array}{c}-0.038 \\
(0.067)\end{array}$ & $\begin{array}{c}0.020 \\
(0.069)\end{array}$ \\
\hline Year 0 & $\begin{array}{c}0.077 * * * \\
(0.029)\end{array}$ & $\begin{array}{c}0.023 \\
(0.067)\end{array}$ & $\begin{array}{c}0.065 \\
(0.052)\end{array}$ & $\begin{array}{c}0.106 * * \\
(0.052)\end{array}$ & $\begin{array}{c}-0.022 \\
(0.077)\end{array}$ & $\begin{array}{c}0.068 \\
(0.090)\end{array}$ \\
\hline Year 1 & $\begin{array}{c}0.041 \\
(0.034)\end{array}$ & $\begin{array}{c}-0.013 \\
(0.071)\end{array}$ & $\begin{array}{c}0.035 \\
(0.060)\end{array}$ & $\begin{array}{c}0.082 \\
(0.058)\end{array}$ & $\begin{array}{c}-0.058 \\
(0.084)\end{array}$ & $\begin{array}{c}0.049 \\
(0.119)\end{array}$ \\
\hline Year 2 & $\begin{array}{c}0.048 \\
(0.050)\end{array}$ & $\begin{array}{c}-0.019 \\
(0.080)\end{array}$ & $\begin{array}{c}0.042 \\
(0.076)\end{array}$ & $\begin{array}{l}0.122 * \\
(0.070)\end{array}$ & $\begin{array}{c}-0.044 \\
(0.097)\end{array}$ & $\begin{array}{c}0.092 \\
(0.149)\end{array}$ \\
\hline Year 3 & $\begin{array}{c}0.071 \\
(0.050)\end{array}$ & $\begin{array}{c}-0.002 \\
(0.078)\end{array}$ & $\begin{array}{c}0.064 \\
(0.087)\end{array}$ & $\begin{array}{c}0.137 \\
(0.086)\end{array}$ & $\begin{array}{c}-0.048 \\
(0.087)\end{array}$ & $\begin{array}{c}0.098 \\
(0.182)\end{array}$ \\
\hline Year 4 & $\begin{array}{c}0.082 \\
(0.057)\end{array}$ & $\begin{array}{c}-0.001 \\
(0.084)\end{array}$ & $\begin{array}{c}0.084 \\
(0.098)\end{array}$ & $\begin{array}{l}0.159 * \\
(0.092)\end{array}$ & $\begin{array}{c}-0.061 \\
(0.093)\end{array}$ & $\begin{array}{c}0.124 \\
(0.203)\end{array}$ \\
\hline Year 5 & $\begin{array}{c}0.097 \\
(0.059)\end{array}$ & $\begin{array}{c}0.006 \\
(0.084)\end{array}$ & $\begin{array}{c}0.108 \\
(0.100)\end{array}$ & $\begin{array}{c}0.178 \\
(0.106)\end{array}$ & $\begin{array}{c}-0.078 \\
(0.095)\end{array}$ & $\begin{array}{c}0.137 \\
(0.206)\end{array}$ \\
\hline Year 6 & $\begin{array}{c}0.160 * * * \\
(0.058)\end{array}$ & $\begin{array}{c}0.053 \\
(0.089)\end{array}$ & $\begin{array}{c}0.176 \\
(0.109)\end{array}$ & $\begin{array}{l}0.213 * \\
(0.113)\end{array}$ & $\begin{array}{c}-0.096 \\
(0.095)\end{array}$ & $\begin{array}{c}0.167 \\
(0.218)\end{array}$ \\
\hline Year 7+ & $\begin{array}{c}0.188 * * \\
(0.082)\end{array}$ & $\begin{array}{c}0.016 \\
(0.095)\end{array}$ & $\begin{array}{c}0.179 \\
(0.113)\end{array}$ & $\begin{array}{c}0.259 \\
(0.162)\end{array}$ & $\begin{array}{c}-0.196 * \\
(0.114)\end{array}$ & $\begin{array}{c}0.156 \\
(0.227)\end{array}$ \\
\hline Time Trends & Linear & Quadratic & Cubic & Linear & Quadratic & Cubic \\
\hline Observations & 18,607 & 18,607 & 18,607 & 15,080 & 15,080 & 15,080 \\
\hline No. of cities & 825 & 825 & 825 & 648 & 648 & 648 \\
\hline No. of states & 50 & 50 & 50 & 49 & 49 & 49 \\
\hline
\end{tabular}

Table A2 lists effects of medical marijuana laws on log violent crime rates in years relative to the law's passage, calculated using linear regressions. All specifications control for city (or state) and year fixed effects, log city (state) populations, log city (state) police officer rates, dummy variables for marijuana decriminalization and legalization, and log state unemployment rates. Robust standard errors allowing within-state clustering are reported in parentheses. ${ }^{* * *} \mathrm{p}<0.01,{ }^{* *} \mathrm{p}<0.05,{ }^{*} \mathrm{p}<0.1$. 
Appendix Table A3: Dynamic Effects of Medical Marijuana Laws on Property Crime

\begin{tabular}{|c|c|c|c|c|c|c|}
\hline & (1) & (2) & (3) & (4) & (5) & (6) \\
\hline & \multicolumn{3}{|c|}{ All cities } & \multicolumn{3}{|c|}{ Without California } \\
\hline Year -5 & $\begin{array}{c}0.037 \\
(0.027)\end{array}$ & $\begin{array}{c}0.037 \\
(0.030)\end{array}$ & $\begin{array}{l}0.045^{*} \\
(0.026)\end{array}$ & $\begin{array}{c}0.014 \\
(0.034)\end{array}$ & $\begin{array}{l}-0.007 \\
(0.024)\end{array}$ & $\begin{array}{c}0.017 \\
(0.025)\end{array}$ \\
\hline Year -4 & $\begin{array}{c}0.056^{* *} \\
(0.024)\end{array}$ & $\begin{array}{c}0.069 * * \\
(0.031)\end{array}$ & $\begin{array}{c}0.090 * * * \\
(0.030)\end{array}$ & $\begin{array}{c}0.034 \\
(0.036)\end{array}$ & $\begin{array}{c}0.022 \\
(0.031)\end{array}$ & $\begin{array}{c}0.057 \\
(0.037)\end{array}$ \\
\hline Year -3 & $\begin{array}{l}0.054^{*} \\
(0.030)\end{array}$ & $\begin{array}{l}0.068^{*} \\
(0.034)\end{array}$ & $\begin{array}{c}0.102^{* *} \\
(0.041)\end{array}$ & $\begin{array}{c}0.038 \\
(0.047)\end{array}$ & $\begin{array}{c}0.020 \\
(0.042)\end{array}$ & $\begin{array}{c}0.070 \\
(0.048)\end{array}$ \\
\hline Year -2 & $\begin{array}{c}0.039 \\
(0.030)\end{array}$ & $\begin{array}{c}0.053 \\
(0.037)\end{array}$ & $\begin{array}{l}0.103 * * \\
(0.047)\end{array}$ & $\begin{array}{c}0.034 \\
(0.051)\end{array}$ & $\begin{array}{c}0.010 \\
(0.048)\end{array}$ & $\begin{array}{c}0.076 \\
(0.062)\end{array}$ \\
\hline Year -1 & $\begin{array}{l}-0.004 \\
(0.036)\end{array}$ & $\begin{array}{c}0.014 \\
(0.045)\end{array}$ & $\begin{array}{c}0.081 \\
(0.058)\end{array}$ & $\begin{array}{c}0.007 \\
(0.061)\end{array}$ & $\begin{array}{c}-0.018 \\
(0.068)\end{array}$ & $\begin{array}{c}0.064 \\
(0.075)\end{array}$ \\
\hline Year 0 & $\begin{array}{c}0.018 \\
(0.042)\end{array}$ & $\begin{array}{c}0.034 \\
(0.045)\end{array}$ & $\begin{array}{c}0.122^{* *} \\
(0.061)\end{array}$ & $\begin{array}{c}0.055 \\
(0.060)\end{array}$ & $\begin{array}{c}0.021 \\
(0.061)\end{array}$ & $\begin{array}{c}0.121 \\
(0.083)\end{array}$ \\
\hline Year 1 & $\begin{array}{l}-0.004 \\
(0.051)\end{array}$ & $\begin{array}{c}0.020 \\
(0.051)\end{array}$ & $\begin{array}{l}0.133^{*} \\
(0.071)\end{array}$ & $\begin{array}{c}0.061 \\
(0.057)\end{array}$ & $\begin{array}{c}0.029 \\
(0.069)\end{array}$ & $\begin{array}{c}0.141 \\
(0.096)\end{array}$ \\
\hline Year 2 & $\begin{array}{c}0.008 \\
(0.062)\end{array}$ & $\begin{array}{c}0.022 \\
(0.062)\end{array}$ & $\begin{array}{l}0.159^{*} \\
(0.084)\end{array}$ & $\begin{array}{c}0.113 * * \\
(0.050)\end{array}$ & $\begin{array}{c}0.058 \\
(0.061)\end{array}$ & $\begin{array}{c}0.181 \\
(0.115)\end{array}$ \\
\hline Year 3 & $\begin{array}{c}0.012 \\
(0.059)\end{array}$ & $\begin{array}{c}0.033 \\
(0.063)\end{array}$ & $\begin{array}{c}0.202 * * \\
(0.087)\end{array}$ & $\begin{array}{c}0.119 * * \\
(0.059)\end{array}$ & $\begin{array}{c}0.068 \\
(0.061)\end{array}$ & $\begin{array}{c}0.202 \\
(0.126)\end{array}$ \\
\hline Year 4 & $\begin{array}{c}0.047 \\
(0.047)\end{array}$ & $\begin{array}{c}0.071 \\
(0.055)\end{array}$ & $\begin{array}{c}0.268 * * \\
(0.100)\end{array}$ & $\begin{array}{l}0.110^{*} \\
(0.062)\end{array}$ & $\begin{array}{c}0.053 \\
(0.073)\end{array}$ & $\begin{array}{c}0.197 \\
(0.143)\end{array}$ \\
\hline Year 5 & $\begin{array}{c}0.075 \\
(0.054)\end{array}$ & $\begin{array}{c}0.108^{*} \\
(0.064)\end{array}$ & $\begin{array}{c}0.338 * * * \\
(0.122)\end{array}$ & $\begin{array}{c}0.120 \\
(0.079)\end{array}$ & $\begin{array}{c}0.066 \\
(0.107)\end{array}$ & $\begin{array}{c}0.221 \\
(0.148)\end{array}$ \\
\hline Year 6 & $\begin{array}{c}0.132 * * \\
(0.054)\end{array}$ & $\begin{array}{c}0.166 * * * \\
(0.061)\end{array}$ & $\begin{array}{c}0.424 * * * \\
(0.136)\end{array}$ & $\begin{array}{c}0.132 \\
(0.087)\end{array}$ & $\begin{array}{c}0.076 \\
(0.118)\end{array}$ & $\begin{array}{c}0.243 \\
(0.158)\end{array}$ \\
\hline Year 7+ & $\begin{array}{l}0.146^{*} \\
(0.074)\end{array}$ & $\begin{array}{c}0.168 * * \\
(0.063)\end{array}$ & $\begin{array}{c}0.476^{* *} \\
(0.179)\end{array}$ & $\begin{array}{c}0.018 \\
(0.103)\end{array}$ & $\begin{array}{l}-0.036 \\
(0.130)\end{array}$ & $\begin{array}{c}0.124 \\
(0.162)\end{array}$ \\
\hline Time Trends & Linear & Quadratic & Cubic & Linear & Quadratic & Cubic \\
\hline Observations & 18,607 & 18,607 & 18,607 & 15,080 & 15,080 & 15,080 \\
\hline No. of cities & 825 & 825 & 825 & 648 & 648 & 648 \\
\hline No. of states & 50 & 50 & 50 & 49 & 49 & 49 \\
\hline
\end{tabular}

Table A3 lists effects of medical marijuana laws on log property crime rates in years relative to the law's passage, calculated using linear regressions. All specifications control for city (or state) and year fixed effects, log city (state) populations, log city (state) police officer rates, dummy variables for marijuana decriminalization and legalization, and log state unemployment rates. Robust standard errors allowing within-state clustering are reported in parentheses. ${ }^{* * *} \mathrm{p}<0.01,{ }^{* *} \mathrm{p}<0.05,{ }^{*} \mathrm{p}<0.1$. 


\section{Appendix Table A4: Synthetic Control Estimates of the Effects of}

Medical Marijuana Laws on Violent Crime by State

\begin{tabular}{lcccccc}
\hline & California & Washington & Oregon & Alaska & Maine & Hawaii \\
\cline { 2 - 7 } MML & $-0.189^{* *}$ & -0.180 & $-0.234^{*}$ & -0.046 & -0.112 & 0.193 \\
P-value & 0.045 & 0.109 & 0.077 & 0.852 & 0.669 & 0.381 \\
No. of cities & 127 & 15 & 11 & 1 & 1 & 1 \\
\hline & & & & & & \\
& Colorado & Nevada & Montana & Rhode Island New Mexico & Michigan \\
\cline { 2 - 7 } MML & 0.050 & 0.071 & $0.362^{*}$ & -0.034 & -0.044 & 0.023 \\
P-value & 0.548 & 0.543 & 0.080 & 0.776 & 0.643 & 0.716 \\
No. of cities & 13 & 5 & 2 & 5 & 4 & 32 \\
\hline & & & & & & \\
& D.C. & New Jersey & Arizona & Delaware & Connecticut & Massachusetts \\
$M M L$ & 0.058 & -0.073 & 0.037 & -0.086 & $-0.129^{*}$ & -0.058 \\
P-value & 0.640 & 0.119 & 0.498 & 0.484 & 0.077 & 0.554 \\
No. of cities & 1 & 36 & 17 & 1 & 19 & 24 \\
\hline
\end{tabular}

Appendix Table A4 lists state average differences between the log violent crime rates of cities with medical marijuana laws and those of their synthetic controls. The p-values reported in the table are calculated using placebo estimates and are two-sided. The order of states is based on the year in which each state's medical marijuana law became legally effective. ${ }^{* * *} \mathrm{p}<0.01,{ }^{* *} \mathrm{p}<0.05,{ }^{*} \mathrm{p}<0.1$.

\section{Appendix Table A5: Synthetic Control Estimates of the Effects of Medical Marijuana Laws on Property Crime by State}

\begin{tabular}{lcccccc}
\hline & California & Washington & Oregon & Alaska & Maine & Hawaii \\
\cline { 2 - 7 } MML & $-0.246^{* * *}$ & 0.000 & 0.007 & 0.009 & 0.113 & 0.015 \\
P-value & 0.000 & 0.997 & 0.923 & 0.955 & 0.524 & 0.936 \\
No. of cities & 127 & 15 & 11 & 1 & 1 & 1 \\
\hline
\end{tabular}

\begin{tabular}{lcccccc} 
& Colorado & Nevada & Montana & Rhode Island New Mexico & Michigan \\
\cline { 2 - 7 } MML & 0.063 & $0.192^{* *}$ & -0.040 & 0.052 & 0.052 & 0.012 \\
P-value & 0.204 & 0.020 & 0.718 & 0.547 & 0.522 & 0.755 \\
No. of cities & 13 & 5 & 2 & 5 & 4 & 32 \\
\hline
\end{tabular}

\begin{tabular}{lcccccc} 
& D.C. & New Jersey & Arizona & Delaware & Connecticut & Massachusetts \\
\cline { 2 - 7 } MML & 0.084 & -0.035 & 0.032 & 0.071 & -0.001 & -0.008 \\
P-value & 0.446 & 0.323 & 0.400 & 0.452 & 0.979 & 0.758 \\
No. of cities & 1 & 36 & 17 & 1 & 19 & 24 \\
\hline
\end{tabular}

Appendix Table A5 lists state average differences between the log violent crime rates of cities with medical marijuana laws and those of their synthetic controls. The p-values reported in the table are calculated using placebo estimates and are two-sided. The order of states is based on the year in which each state's medical marijuana law became legally effective. ${ }^{* * *} \mathrm{p}<0.01,{ }^{* *} \mathrm{p}<0.05,{ }^{*} \mathrm{p}<0.1$. 


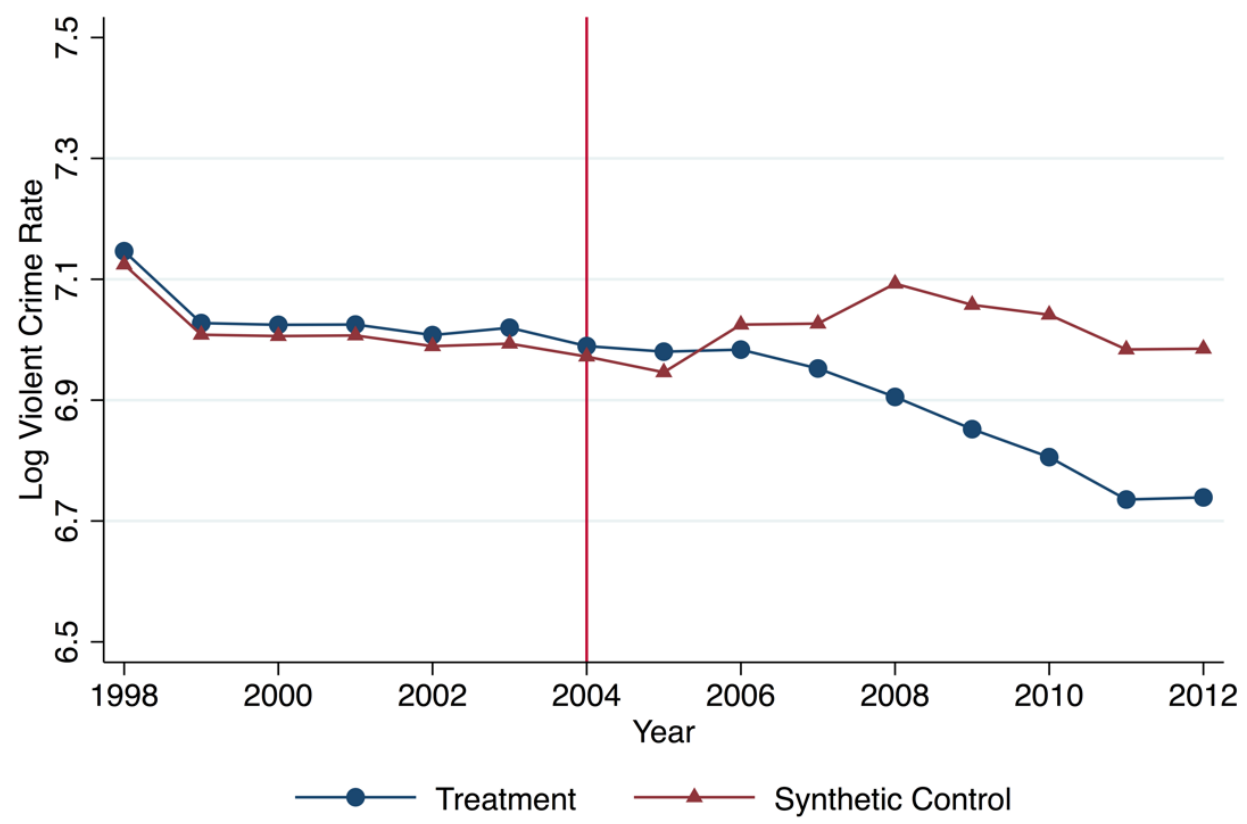

Difference-in-difference estimate: -0.171

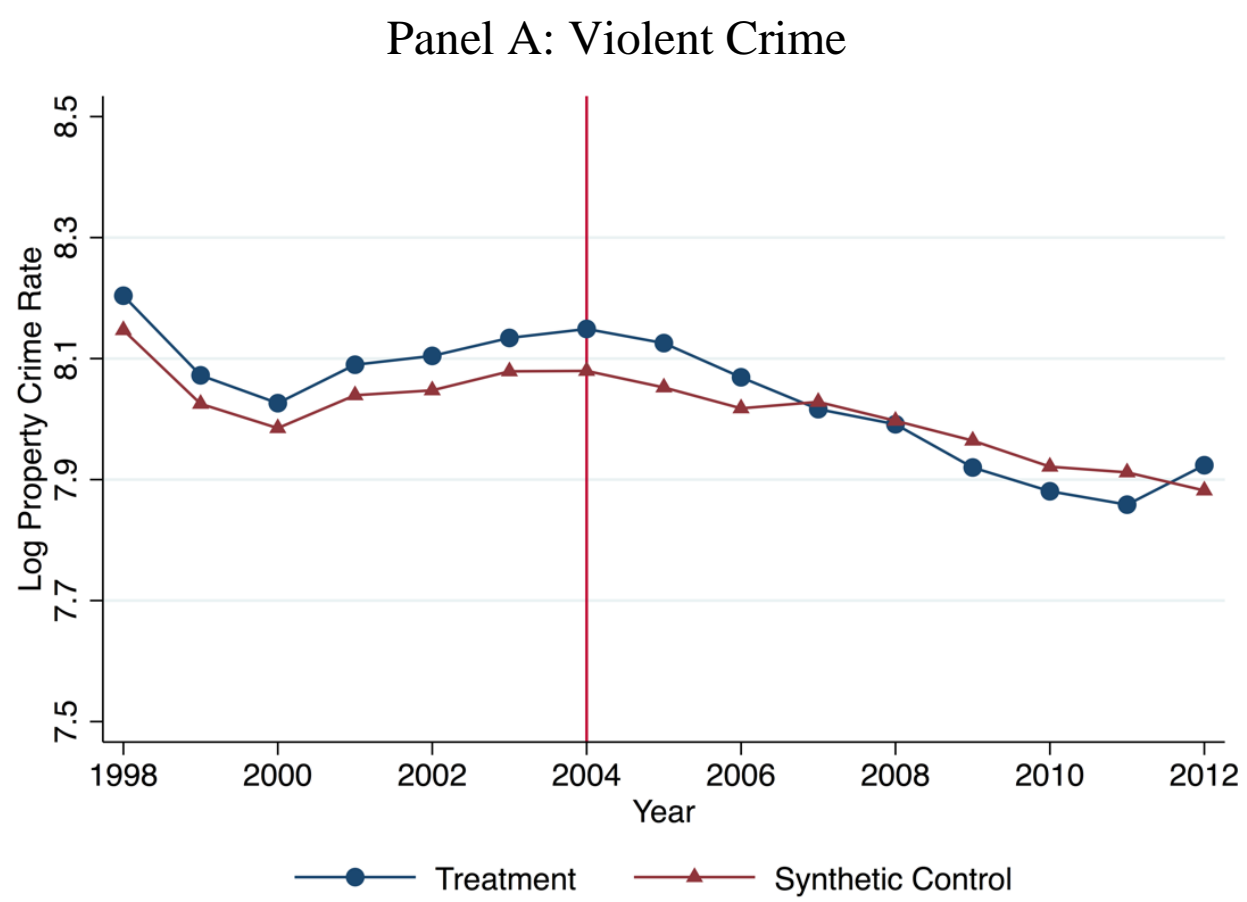

Difference-in-difference estimate: -0.053

Panel B: Property Crime

\section{Appendix Figure A1: Crime Rates Before and the California Medical Marijuana Law Amendment}

Appendix Figure A1 displays mean log crime rates per 100,000 residents for California and its synthetic control, with the synthetic control matched on years prior to the 2004 passage of the Senate Bill 420. The top panel presents log violent crime rates whereas the bottom presents log property crime rates. 


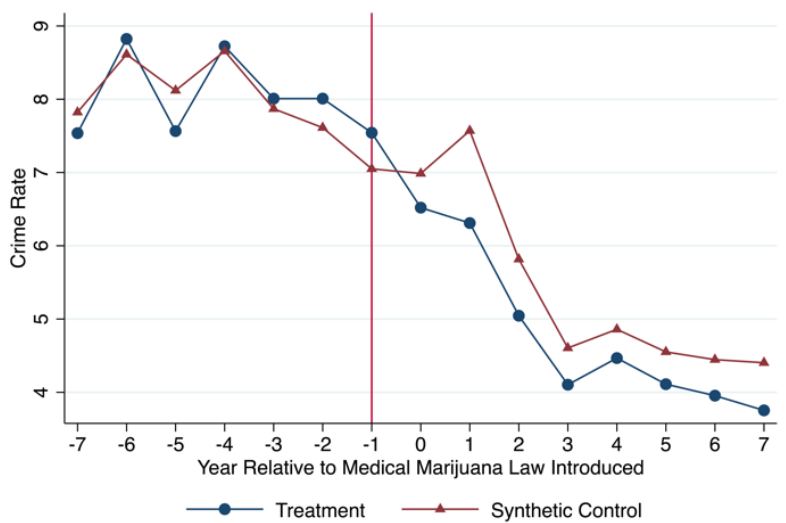

Difference-in-difference estimate: -0.69 (pre-MML average: 8.03 )

\section{Panel A: Murder}

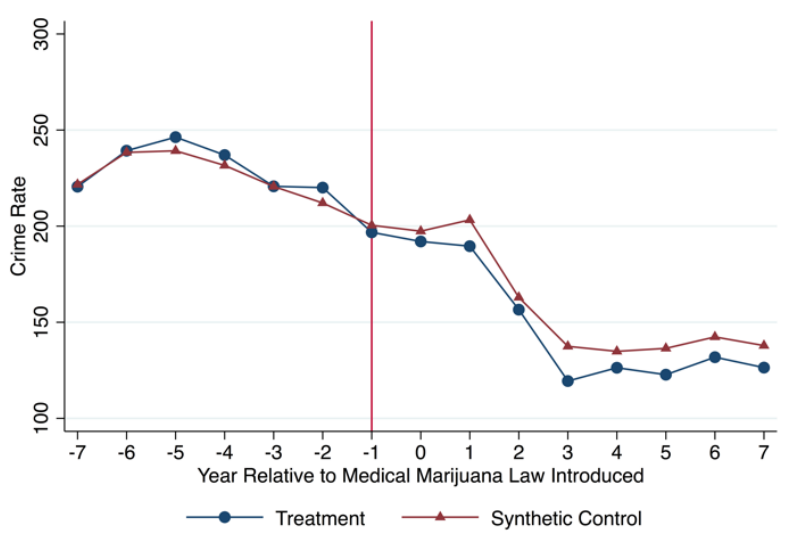

Difference-in-difference estimate: -13.34 (pre-MML average: 225.82)

Panel C: Robbery

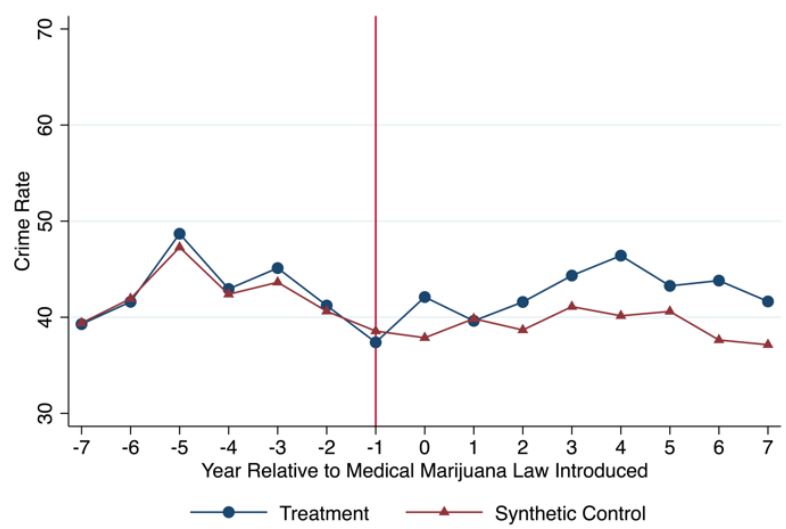

Difference-in-difference estimate: 3.38 (pre-MML average: 42.32)

Panel B: Rape

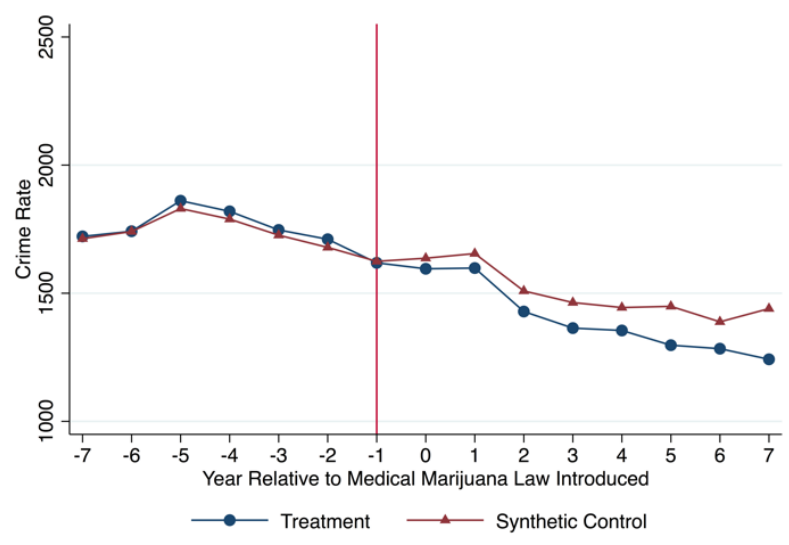

Difference-in-difference estimate: -119.48 (pre-MML average: 1745.79)

Panel D: Assault

\section{Appendix Figure A2: Specific Violent Crime Rates Before and After Medical Marijuana Laws}

Appendix Figure A2 displays mean crime rates per 100,000 residents across states which implemented medical marijuana laws and across their synthetic controls. Each panel displays crime rates for a particular class of violent crime. 


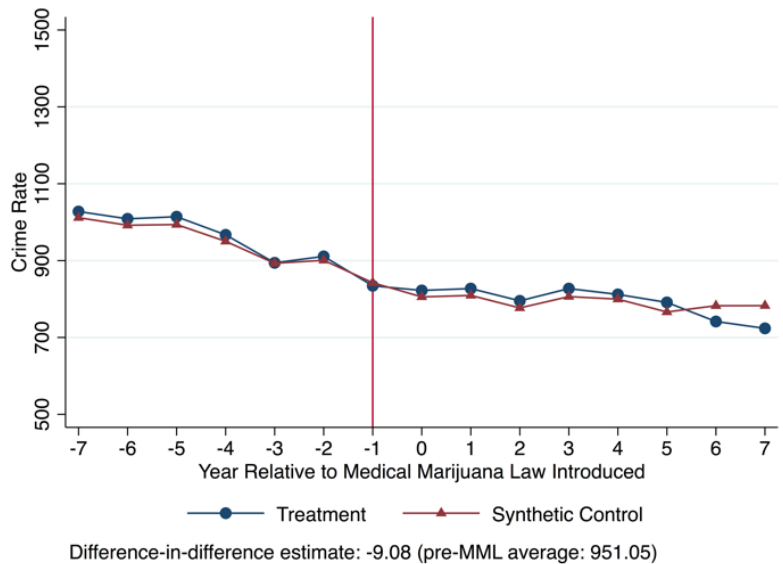

Panel A: Burglary

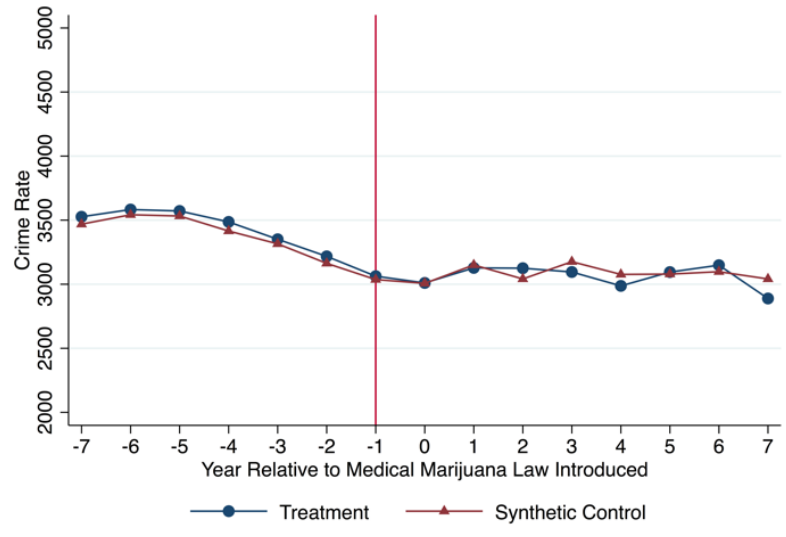

Difference-in-difference estimate: -70.43 (pre-MML average: 3399.88 )

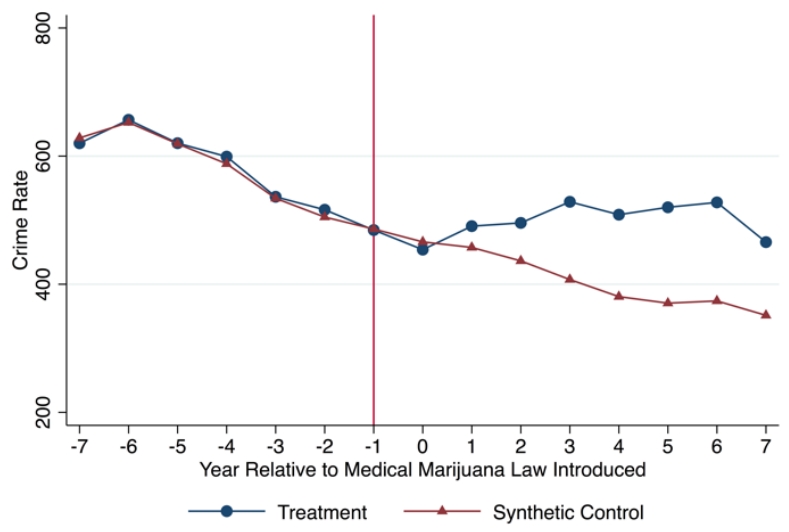

Difference-in-difference estimate: 90.52 (pre-MML average: 576.21 )

\section{Panel C: Auto Theft}

\section{Appendix Figure A3: Specific Property Crime Rates Before and After Medical Marijuana Laws}

Appendix Figure A3 displays mean crime rates per 100,000 residents across states which implemented medical marijuana laws and across their synthetic controls. Each panel displays crime rates for a particular class of property crime. 